\title{
Life-assessment technology for fossil power plants
}

\author{
R VISWANATHAN \\ Electric Power Research Institute, 3412 Hillview Avenue, Palo Alto, Cali- \\ fornia 94303, USA
}

\begin{abstract}
During the last decade, construction of new fossil power plants has come to a virtual halt in the United States. The main factors responsible for this situation are: (1) industry perception of the existence of sufficient reserve margins, (2) uncertainty in forecasting load growth, (3) cost of borrowing for new plant construction, (4) siting and licensing problems for new plants, and (5) the applicability of more stringent environmental standards for new plants. Unfortunately, by the year 2000 it is estimated that nearly $20 \%$ of all the fossil units will be more than 40 years old, and almost $44 \%$ will be more than 30 years old. Based on historical trends, nearly half of all fossil plants have been retired before their fortieth year and three quarters before serving 50 years. In the future this trend is unlikely because of the shrinking reserve margins and the long lead time for new capacity addition. If the life of these aging plants can be extended by $20-30$ years, utilities can have a viable low-cost alternative to building new plants while at the same time circumventing some of the regulatory, siting and licensing constraints. In view of this, plant life extension has become an integral part of the planning strategy for many US utilities. A critical component of the Electric Power Research Institute's (EPRI) efforts in formulating life extension strategies for fossil power plants is the development of techniques to assess the current condition of high-temperature components. These techniques are necessary not only for assessment of the remaining life, but also for avoiding catastrophic failures and forced outages, for setting up inspection intervals and for optimizing the operating procedures. The components that are being addressed at present are boiler pressure parts, steam pipes and steam turbine rotors. This paper will provide a brief overview of current concerns and areas of research where significant progress has been made to address these concerns from a phenomenological point of view.
\end{abstract}

Keywords. Life-assessment technology; fossil power plants; life extension strategies.

\section{Introduction}

Components operating at elevated temperatures can fail due to excessive deformation, bursting under pressure, or cracking under pure creep or creep-fatigue conditions. 
Failure by cracking may further be viewed as consisting of three stages: crack initiation, crack propagation, and final failure of the component once the crack reaches a critical size. Life-assessment techniques are, therefore, aimed at quantifying uniform or localized incipient damage prior to crack initiation, the rate at which cracks grow, and the critical crack size that will lead to final failure. Eventual failure of the component can occur either by leakage or rupture at the operating temperature or by rapid brittle fracture at lower temperatures during start-up/shutdown transients. In the latter case, the critical size of the crack is defined by the fracture toughness of the material. Since embrittlement phenomena occurring in service can reduce the toughness of the material, knowledge of fracture toughness in the service-exposed condition is necessary.

Based on worldwide experience during the last five years, a three-level approach for life assessment has evolved. In this approach, simple calculational techniques are used in the first level, followed by nondestructive and destructive tests in the next two levels. The focus of research has been mainly to reduce the uncertainties and hence the conservatism in each of the levels of assessment. This article is an overview of advances during the last five years in refining the assessment procedures under each of these levels, with special emphasis on results of work sponsored by the Electric Power Research Institute (EPRI). A more complete review of the extensive body of relevant literature may be found in Viswanathan (1989). While this paper will review advancements from a generic technology point of view, specific techniques applicable to individual components such as turbine rotors, steam pipes, headers and tubes may be found in other key overview papers (Becker et al 1987; Harris et al 1993; Viswanathan \& Wells 1993; Wells \& Viswanathan 1993; Viswanathan et al 1994).

\section{Calculation techniques}

In the calculational procedures, plant records and the time-temperature history of the component are reviewed. The creep or creep-fatigue life fraction consumed is calculated using assumed material properties and damage rules. This procedure is usually inaccurate due to errors in assumed history, in the material properties, and in the damage rules. The temperature-history information may be refined by supplemental nondestructive or destructive examinations such as microstructural studies, hardness measurements, and oxide-scale measurements. The uncertainties in material properties can be reduced by building a database, particularly with respect to service-retrieved components taking into account the environmental effects. The limitations of the damage rules have also been explored based on extensive laboratory studies.

\subsection{Life fraction rule for creep}

The Life Fraction Rule (LFR) states that at failure

$$
\sum t_{i} / t_{r}=1 \text {, }
$$

where $t_{i}$ is the time spent at a given stress and temperature, and $t_{r}$ is the rupture life for the same test conditions. When the damage fractions incurred under different sets of stress-temperature conditions add up to unity, failure is presumed to occur. Hart (1976), Woodford (1979), and Bolton et al (1980) have demonstrated that the LFR is 
valid for temperature changes but not for stress changes. In a multiclient project recently completed at ERA Technology, an extensive body of long-time data has been generated, with the specific intent of verifying the LFR for varying temperature conditions (Brear \& McCarthy 1989) and the results have been analysed in detail by Viswanathan (Viswanathan \& Gehl 1992). Two heats of a $0.5 \mathrm{Cr}-0.5 \mathrm{Mo}-0.25 \mathrm{~V}$ steel were evaluated: a pipe-grade steel with a predominantly ferritic microstructure and relatively high ductility ( $15 \%$ elongation) under long-term service conditions, designated MG, and a cast turbine casing steel with a bainitic microstructure and low ductility (3.5\% elongation), designed FW. In addition, a ductile tubing steel of $21 / 4 \mathrm{Cr}-1$ Mo steel designated heat RG was also evaluated.

Specimens from heat MG were subjected to creep damage fractions of $0.25,0.45,0.63$, and 0.82 at $575^{\circ} \mathrm{C}$ at a stress of $69.5 \mathrm{MPa}$; specimens from heat $\mathrm{FW}$ were also subjected to similar levels of initial creep damage by testing at $550^{\circ} \mathrm{C}$ and $84.9 \mathrm{MPa}$. The predamaged samples were then subjected to accelerated rupture testing at higher temperatures, holding the stress at the same level as in the initial creep damage tests.

Results of the accelerated stress rupture tests on heat MG at $69.5 \mathrm{MPa}$ for the virgin condition and for the predamaged conditions are shown in figure 1 . The target values of remaining life at $575^{\circ} \mathrm{C}$ based on the LFR are also indicated. If the $L F R$ is valid, the temperature vs. time-to-rupture lines should be parallel to the virgin material line and should pass through the respective target values. This is clearly not the case; linear

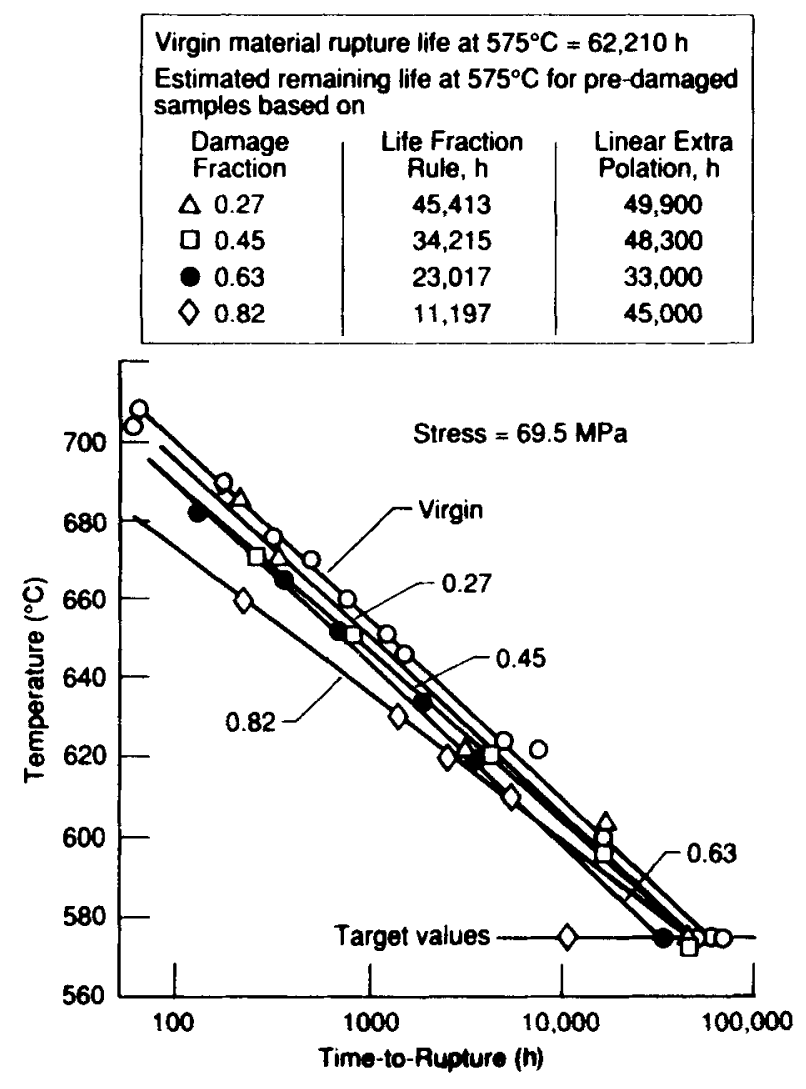

Figure 1. Stress rupture curves for heat MG in the virgin condition and after prior creep damage to various life fractions. 
extrapolation of the accelerated-test data predicted remaining lives at $575^{\circ} \mathrm{C}$ in excess of the target value in every case. For the 0.82 predamaged samples, the accelerated-test results grossly over-predicted the remaining life compared to the calculated value based on the LFR.

The trend, for the brittle cast FW (see figure 2) is exactly opposite to that observed for the ductile heat MG. With the exception of the 0.45 predamaged sample, for all other samples, the predictions from the accelerated tests fell short of the target values calculated from the LFR.

A third heat of $21 / 4 \mathrm{Cr}-1 \mathrm{Mo}$ steel (designated RG) in the normalized and tempered condition was used for the program. Tube samples of the steel were pressurized to an equivalent stress of $116 \mathrm{MPa}(16.6 \mathrm{ksi})$ and tested to creep life fractions of 0.5 and 0.72 at $525^{\circ} \mathrm{C}\left(975^{\circ} \mathrm{F}\right)$, the mean rupture life being $45,475 \mathrm{~h}$ in the burst tests. From the interrupted test tubes, chordal samples were machined and subjected to accelerated tests, uniaxially at a constant stress of $16.6 \mathrm{ksi}(116 \mathrm{MPa})$, at a number of temperatures in the range of 550 to $650^{\circ} \mathrm{C}\left(1025^{\circ} \mathrm{F}\right.$ to $\left.1200^{\circ} \mathrm{F}\right)$. Some tests were also carried out at $525^{\circ} \mathrm{C}\left(975^{\circ} \mathrm{F}\right)$ to enable comparison of the actual remaining life at $525^{\circ} \mathrm{C}\left(975^{\circ} \mathrm{F}\right)$ with those predicted by the LFR and from isostress extrapolation. Results of these rupture tests are shown in figure 3. The uniaxial rupture life for the virgin material was shorter than the burst test lives $(30,094 \mathrm{~h}$ vs $45,475 \mathrm{~h})$ indicating that the mean diameter hoop stress formula resulted in an overestimation of the equivalent stress. For the predamaged samples, the actual remaining test lives at $525^{\circ} \mathrm{C}$ agreed very closely with

Virgin material rupture the a $550^{\circ} \mathrm{C}=67,726 \mathrm{~h}$

Estimated remaining life at $550^{\circ} \mathrm{C}$ for pre-damaged samples based on

\begin{tabular}{|c|c|c|}
\hline $\begin{array}{l}\text { Damage } \\
\text { iraction }\end{array}$ & $\begin{array}{l}\text { Life fraction } \\
\text { rule. (h) }\end{array}$ & $\begin{array}{l}\text { Linear } \\
\text { extrapolation. (h) }\end{array}$ \\
\hline $\begin{array}{l}0.26 \\
0.45 \\
0.63 \\
0.91\end{array}$ & $\begin{array}{l}50.132 \\
37.260 \\
25.066 \\
12.871\end{array}$ & $\begin{array}{l}32.000 \\
62.000 \\
18.000 \\
10.000\end{array}$ \\
\hline
\end{tabular}

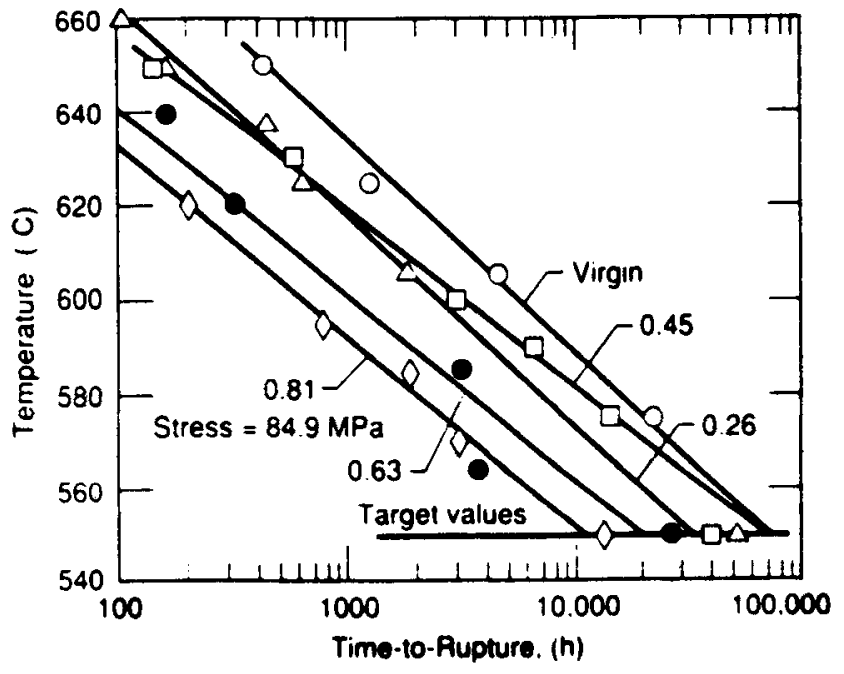

Figure 2. Stress rupture curves for heat $F W$ in the virgin condition and after prior creep damage to various life fractions. 


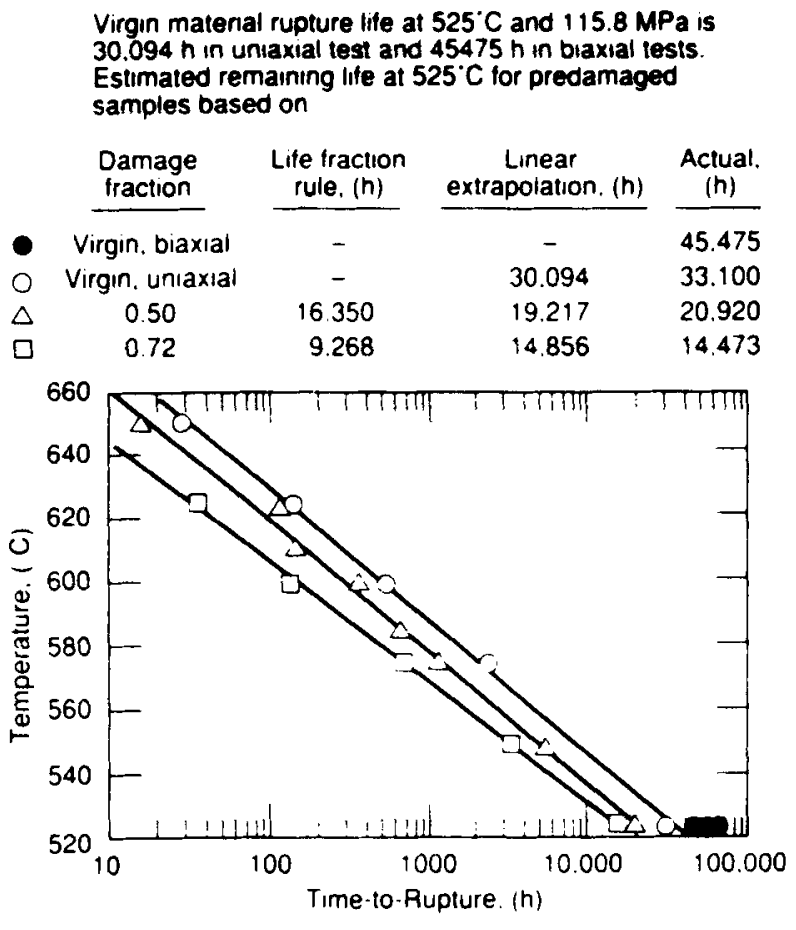

Figure 3. Results of tube burst tests and uniaxial accelerated isostress rupture tests on samples machining from tubes previously subjected to 0.5 and 0.72 life fraction creep damage, $21 / 4$ Cr-Mo steel (Heat RG).

those estimated from the remaining life fraction using the life fraction rule and from linear extrapolation of the accelerated test results.

A correlation between the expected life based on the LFR and the observed life for the three heats (figure 4) shows that for the brittle material, the actual life is always shorter than the expected life while the opposite is true for the ductile heat MG. For the ductile heat RG of $21 / 4 \mathrm{Cr}-1 \mathrm{Mo}$ steel, the expected life agrees closely with the observed life in the accelerated tests.

The difference in behaviour between the brittle and ductile cases is believed to result from differences in damage mechanisms. Prior creep damage in the brittle case consisted of "mechanical damage" with extensive formation of creep cavities. In the ductile case, damage was "metallurgical" damage consisting of microstructural changes. In the brittle steel, subsequent testing by temperature acceleration presumably resulted in rapid linkup of cavities, leading to premature failure; in the ductile steel, on the other hand, temperature acceleration presumably led to recovery of some of the metallurgical damage, resulting in increased life.

The correlation between prior expended life fraction and remaining life fraction measured in the accelerated tests shown in figure 5 may be used as a modified basis for LFR. For a ductile material, the LFR may be used for a conservative prediction of remaining life. For a brittle material, a value of $<1$ as defined by the lower-bound envelope in figure 6 may be used as a conservative failure criterion.

For a ductile material, the implications of the above results to actual situations in which the LFR is invoked are as follows: When LFR is used to calculate cumulative damage under conditions where the average metal temperature increases with service 


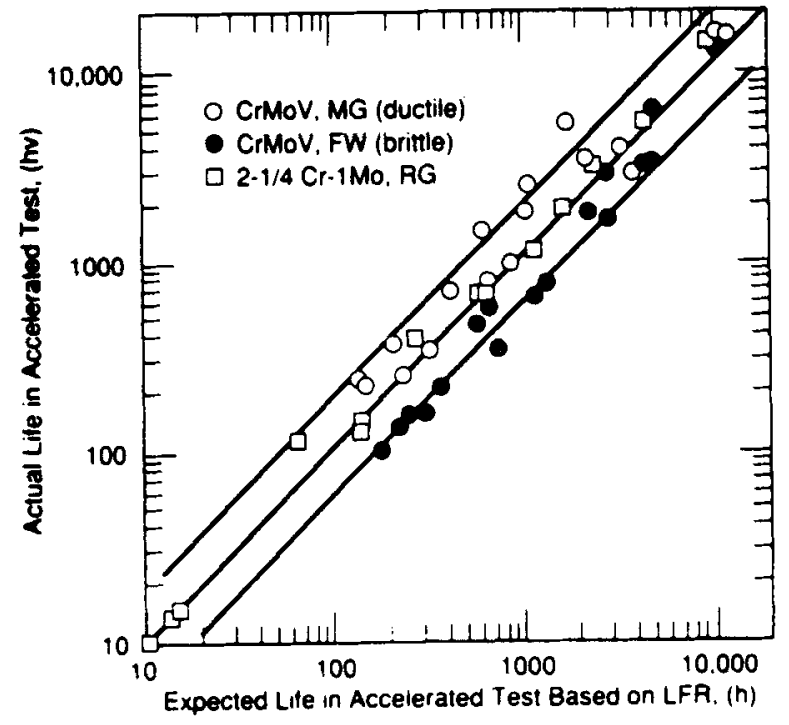

Figure 4. Correlation between expected life based on life fraction rule and actually observed life in post exposure accelerated test.

time (e.g., superheater tubes), failure will always occur at $\Sigma t_{i} / t_{r}>1$. Hence, $\Sigma t_{i} / t_{r}=1$ should be used as a conservative failure criterion. The same reasoning may be applied to situations where periodic temperature excursions occur.

In all life-fraction calculations, the virgin material behaviour (minimum or mean of the International Organization for Standardization's [ISO's] Larson-Miller data) is used as the reference condition for calculating the $t_{r}$. In reality, as the component softens, the applicable Larson-Miller curve is continuously changing in such a way

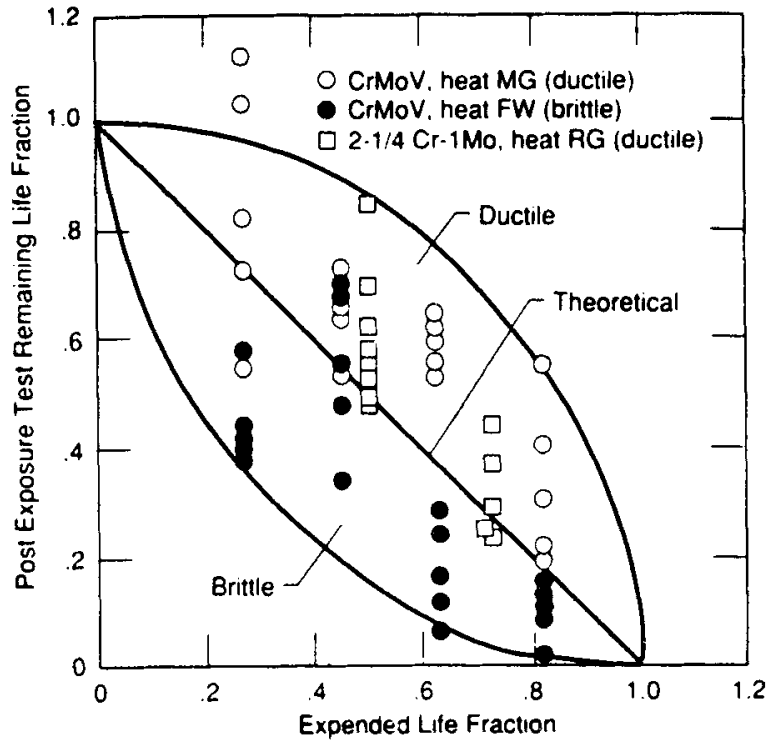

Figure 5. Expended life fraction under service conditions vs. the remaining life fraction as determined from post exposure accelerated tests for 3 heats of steel. 

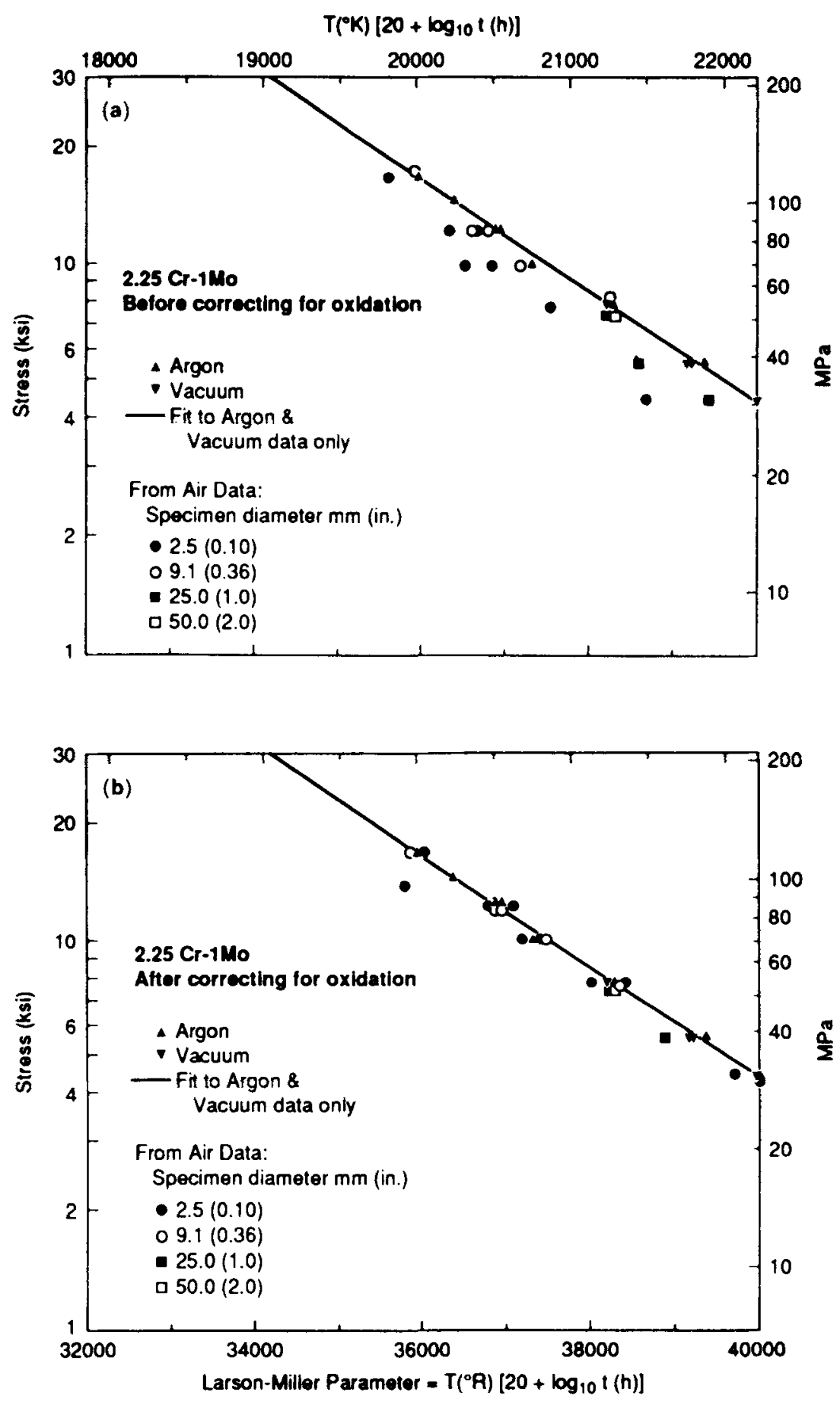

Figure 6. Larson-Miller stress rupture curve for 2-1/4 Cr-1 Mo steel specimens of different sizes, before (a) and after (b) correcting for oxidation effects associated with specimen size. 
that the actual cumulative damage can be more than that calculated by using the virgin material curve. Application of the LFR could be improved by taking the softening reactions into account.

\subsection{Linear damage rule for creep fatigue}

A variety of rules have been enunciated for calculating total damage when both creep and fatigue damage are present in a component. The most popular among these is the linear damage rule, in which the life fractions consumed in creep $\left(t / t_{r}\right)$ and fatigue $\left(N / N_{f}\right)$ are added as follows:

$$
\Sigma\left(N / N_{f}\right)+\Sigma\left(t / t_{r}\right)=D
$$

Differing approaches to calculating $N / N_{f}, t / t_{r}$ and the value of $D$ at failure have led to alternate rules which have been extensively discussed earlier (1989).

An extensive critique of damage rules as they apply to fossil plant components has been published by Viswanathan $(1992,1993)$. Detailed review of literature shows that there are divergent opinions regarding which damage approach provides the best basis for life prediction. It is quite clear that a number of variables, such as test temperature, strain range, frequency, time and type of hold, waveform, ductility of the material, and damage characteristics, affect the fatigue life. The conclusions drawn in any investigation may therefore apply only to the envelope of material and test conditions used in that study. The validity of any damage approach has to be examined with reference to the material and service conditions relevant to a specific application. Broad generalizations based on laboratory tests, which often may have no relevance to actual component conditions, do not appear to be productive. Thus, one should use a tailored, case-specific approach for any given situation.

One of the major problems in evaluating the applicability of different life-prediction methods is that in many cases it is necessary to use all the available data in deriving the life-prediction method and thus it is possible to examine only the accuracy with which a given method describes the data. There also is a scarcity of instances in which service experience has been compared with specific life-prediction methods. In general, the available methods are utilized only to predict the lives of samples tested under laboratory conditions. Validation against component test data in the laboratory and in-service monitoring of actual equipment would lead to more confidence in the use of the various rules.

Results from most studies show that even the best of the available methods can predict life only to within a factor of 2 to 3 . Some of the cited reasons for these inaccuracies have already been discussed. Some additional reasons are: failure of the methods to model changing stress-relaxation and creep characteristics caused by strain softening or hardening, use of monotonic creep data instead of cyclic creep data, and lack of sufficiently extended-duration test data. None of the damage rules available today is entirely based on sound mechanistic principles. They are all phenomenological in nature, involving empirical constants that are material-dependent and difficult to evaluate. Extrapolation of the rules to materials and conditions outside the envelope covered by the specific investigation often results in unsuccessful life predictions. Material behaviour under isothermal LCF conditions in the laboratory often turns out to be totally irrelevant to material behaviour under thermochemical fatigue cycles involving in-phase or out-of-phase thermal cycles in the field. For application to service 
components, the stress-strain variation for each type of transient and its time dependence must be known with accuracy. Such calculations are difficult and expensive to perform. Because of these limitations and the simplicity of the linear-damage summation using the life-fraction rule, the latter approach continues to enjoy widespread popularity in engineering applications.

\subsection{Oxidation and specimen size correction}

The effect of oxidation on rupture life is relevant in several aspects of remaining-life assessment, particularly for heavy-section components with wall thickness values exceeding $25 \mathrm{~mm}$. Rupture life databases used in original design, such as the ISO, ASTM, and National Research Institute for Metals' (NRIM) databases, are based on test data generated on small specimens with diameters of $6-10 \mathrm{~mm}$. When these data are utilized in remaining-life-fraction calculations, conservative results are obtained. In addition, when standard ASTM specimens of $10 \mathrm{~mm}$ or less diameter extracted from heavy-walled piping are tested in air for remaining-life assessment, the resulting values are likely to be conservative. Results of isostress rupture tests conducted at elevated temperatures may need to be corrected for oxidation effects.

An extensive study of oxidation corection factors (CFs) for $2 \cdot 25 \mathrm{Cr}-1 \mathrm{Mo}$ steels has been published by Nakashiro et al (1991). Oxidation correction factors were developed based on oxidation kinetics derived from literature and based on loss of diameter actually observed on samples. Using the correction factor, the original NRIM LarsonMiller plot based on $6 \mathrm{~mm}$ diameter specimens was revised to reflect the behaviour of standard $10 \mathrm{~mm}$ specimens. This study was, however, confined to tubing applications; specimen sizes beyond $10 \mathrm{~mm}$ were not addressed.

An alternate approach for developing OCFs consisted of rupture testing specimens of varying size $(2 \cdot 5-50 \mathrm{~mm})$ (Brear 1994). Selective tests were also carried out on $9 \mathrm{~mm}$-diameter specimens in argon. Preliminary results from one heat of $2 \cdot 25 \mathrm{Cr}-1 \mathrm{Mo}$ steel (heat $\mathrm{BSH}$ ) have shown that the rupture life in air is increased by increasing the specimen size from 2.5 to $9 \mathrm{~mm}$ with a further increase of life in argon as shown in figure 6a. Foulds \& Viswanathan (1994) have analysed these data and developed a methodology for rationalizing the specimen size effect. In the method, the following phenomenological aspects of creep/rupture were utilized:

$$
\dot{\varepsilon} t_{r}=C \text { (Monkman Grant Law), }
$$

where the constant $C$ may vary from test to test and need not be of known value.

$$
\dot{\varepsilon}=B \sigma^{n} \exp (A / T)(\text { Norton Law) }
$$

where the values of the constants $B$ and $A$ need not be known. ' $n$ ' may be measured easily over short test duration and

$$
\int_{0}^{t_{r}}(\dot{\varepsilon} \mathrm{d} t) / C=1
$$

where $\dot{\varepsilon}$ is time-dependent and specimen-size dependent as a function of oxide formation. The equation is based on the assumption that the Robinson Life Fraction Rule applies to the test specimen when one test specimen is represented by multiple, individual test specimens with a reducing size in time. 
The resulting closed form after integrating and solving for $t_{R}$ (in vacuum) is:

$$
\begin{aligned}
t_{R}(\text { corrected })= & r_{0}^{2 n}\left[\frac{1 \cdot 6}{k(1-n)}\left\{r_{0}-\left(\frac{k t_{r}}{1 \cdot 6}\right)^{1 / 2}\right\}^{2(1-n)}\right. \\
& \left.-\frac{3 \cdot 2 r_{0}}{k(1-2 n)}\left\{r_{0}-\left(\frac{k t_{r}}{1 \cdot 6}\right)^{1 / 2}\right\}^{1-2 n}+\frac{1 \cdot 6 r_{0}^{2(1-n)}}{k(1-n)(1-2 n)}\right]
\end{aligned}
$$

where $k$ is the parabolic constant for oxide growth in air, $t_{R}$ is the predicted vacuum test life, $t_{r}$ is the measured air test rupture time, and $r_{0}$ is the initial specimen radius. The constants 1.6 and 3.2 arise from a Pilling-Bedworth assumption of 2.0 .

When (6) is applied to the data shown in figure 6 all the data collapse onto a single line, regardless of specimen size as shown in figure $6 \mathrm{~b}$.

\section{Nondestructive techniques for characterizing damage}

Conventional nondestructive evaluation (NDE) methods fail to detect incipient damage, which can be a precursor to crack initiation and subsequent rapid failure. Several improved NDE techniques have recently been developed for estimating life consumption. These include strain-monitoring techniques, microstructural techniques, hardness-based techniques, and oxide-scale measurement techniques for superheater/ reheater tubes.

\subsection{Strain monitoring}

Strain measurements are often employed to detect creep damage. Gross changes such as header swelling and rotor bore expansion have been monitored in the past. Frequently, due to unknown variations in the original dimensions, changes in dimensions cannot be determined with confidence. Dimensional measurements fail to provide indications of highly damaging and localized creep strains such as those in the heat-affected zones of welds and regions of stress concentrations, in the base metal. Cracking can frequently occur without manifest overall strain Furthermore, the critical strain accumulation preceding fracture can vary widely with a variety of operational material parameters, and with stress state. To enable measurement of localized strains, an "off-line" condition surveillance system has been developed. The system uses the replication principle to evaluate localized strains and life consumption (Cane \& Bissall 1986). A surface grid is scribed at the region of interest and preserved by means of an oxidation-resistant coating. A hard replica of high stability is used to duplicate the grid. Biaxial strain assessment is then made by high-resolution measurement of the replicas taken at successive plant inspection shutdowns. A predictive strain-rate lifetime model approach is used to establish "fitness for service." No field experience with this technique has been reported.

\subsection{Hardness-based techniques for creep damage assessment}

The changes of hardness in low-alloy steels as a function of time and temperature have been extensively quantified, so that hardness changes can be used to estimate the 
operating temperature (Askins 1989; Ellis et al 1989). Correlations have also been established between tensile (hence hardness) and the Larson-Miller rupture relationships for low-alloy steels. These correlations enable selection of the appropriate Larson-Miller plot corresponding to a given hardness level, which can be used to calculate the remaining life.

Current procedures do not recognize that the Larson-Miller parameter for rupture decreases with in-service aging. A model that explicitly takes into account the decreased rupture life due to softening has recently been developed for $2.25 \mathrm{Cr}-1 \mathrm{Mo}$ steels by Grunloh \& Ryder (1989). The effect of aging on creep rupture endurance is modelled by the incorporation of the ultimate tensile strength at room temperature (UTS) into the second-degree polynomial shown in (7), which was derived by analysis of a large body of data, shown in figure 7 .

$$
\mathrm{LMP}_{\text {(rupture) }}=40,975+57(\mathrm{UTS})-5,225(\log \sigma)-2,450(\log \sigma)^{2} .
$$

In this equation, time, temperature, and stress are in units of hours, $\mathbf{R}$ (deg. Rankine), and $\mathrm{ksi}(1 \mathrm{ksi}=6.89 \mathrm{MPa})$, respectively. The effect of aging is taken into account by applying an aging correction factor to the original UTS, based on known kinetics of aging for the steel. Using temperature, applied stress, and starting UTS as input, a computer code calculates the LMP for rupture in the aged condition (and hence $t_{r}$ ) at 1,000 hour intervals. The incremental damage for each time step, and hence the cumulative damage $t / t_{r}$, can be calculated. Kimura and others developed a similar approach to calculate creep life consumption of $\mathrm{CrMoV}$ rotors (Kimura et al 1988) and casings (Fujiyama et al 1990).

Goto and others have proposed using hardness as a stress indicator in the remaininglife assessment of CrMoV rotors (Goto 1985; Kadoya et al 1985). They have quantified the effect of stress on the aging process so that by comparing the kinetics of hardness

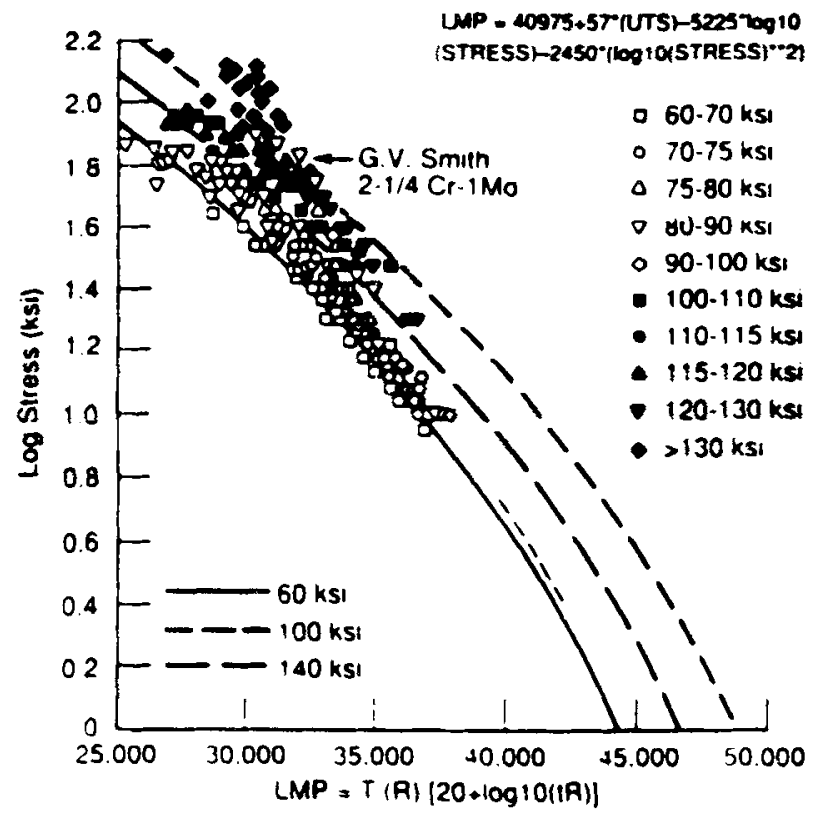

Figure 7. 2-1/4 Cr-1 Mo rupture data showing UTS dependence. 
change in the rotor with that of thermally aged samples, the local stress can be determined. This value of stress and the known value of service temperature are used in conjunction with the Larson-Miller rupture plot to estimate $t_{r}$ for the material in its current damage state.

In contrast, McGuire \& Gooch (1989) show that the magnitude of the stress is unimportant once a "threshold stress level" has been exceeded. For all stress levels in the range $70-240 \mathrm{MPa}$, the hardness change in the stressed condition was found to be $21 \%$ higher compared to the change in the unstressed condition.

A creep model incorporating structural degradation as monitored by hardness changes has been proposed by Cane \& Bissall (1986). By equating the kinetics of hardness change to the kinetics of interparticle spacing changes, the decrease in the threshold back stress for creep is modelled. Substitution of the threshold back stress in the Norton creep law yields an expression for secondary creep rate $\varepsilon$ in terms of hardness changes. By integrating the $\varepsilon$ between $t=0$ and $t=t_{r}$, where $t_{r}$ is the time to failure in terms of the time to reach an arbitrarily chosen critical strain, the remaining rupture life is predicted. The model is currently based on limited data and involves numerous assumptions that can only be justified by further research.

\subsection{Hardness and low-cycle fatigue life}

Considerable work has been carried out (Goto 1985; Kadoya et al 1985; Kimura et al 1988; Fujiyama et al 1990) in applying hardness for calculation of fatigue-life consumption in CrMoV rotor grooves. It has been observed that low-cycle fatigue damage results in strain softening and can be measured as a hardness decrease. The premise, therefore, is that if the fatigue curve corresponding to the current hardness (in service) could be defined, the fatigue-life fraction consumed could be calculated by entering the appropriate total strain range $\Delta \varepsilon_{\text {, }}$ versus number of cycles to crack initiation $\left(N_{f}\right)$ curve, as shown in figure 8 (Kimura et al 1988). These relationships have been quantified (Kimura et al 1988):

where

$$
\Delta \varepsilon_{t}=k_{1} N_{f}^{a_{1}}+k_{2} N_{f}^{a_{2}}
$$

$$
\begin{aligned}
\log k_{1} & =2.59 \times 10^{-3} \mathrm{Hv}-0.9 \quad \text { and } k_{2}=22.0, \\
\alpha_{1} & =1.64 \times 10^{-4} \mathrm{Hv}-0.09 \text { and } \alpha_{2}=0.59, \\
\sigma_{y d} & =1.07 \mathrm{H}_{v}-40.6
\end{aligned}
$$

where $k_{1}$ and $\alpha_{1}$ are hardness-dependent constants, and $\sigma_{y d}$ is the cyclic yield strength. For any given hardness of the steel, (8)-(11) can be used to calculate fatigue-life fraction consumed under different transients, and these fractions can be summed up to calculate the total fatigue-life expenditures using the procedures detailed by Kimura et al (1988).

\subsection{Creep cavitation model}

Metallographic methods have been developed that can correlate either cavitation evolution or changes in carbide spacings with creep-life expenditure. It has been 


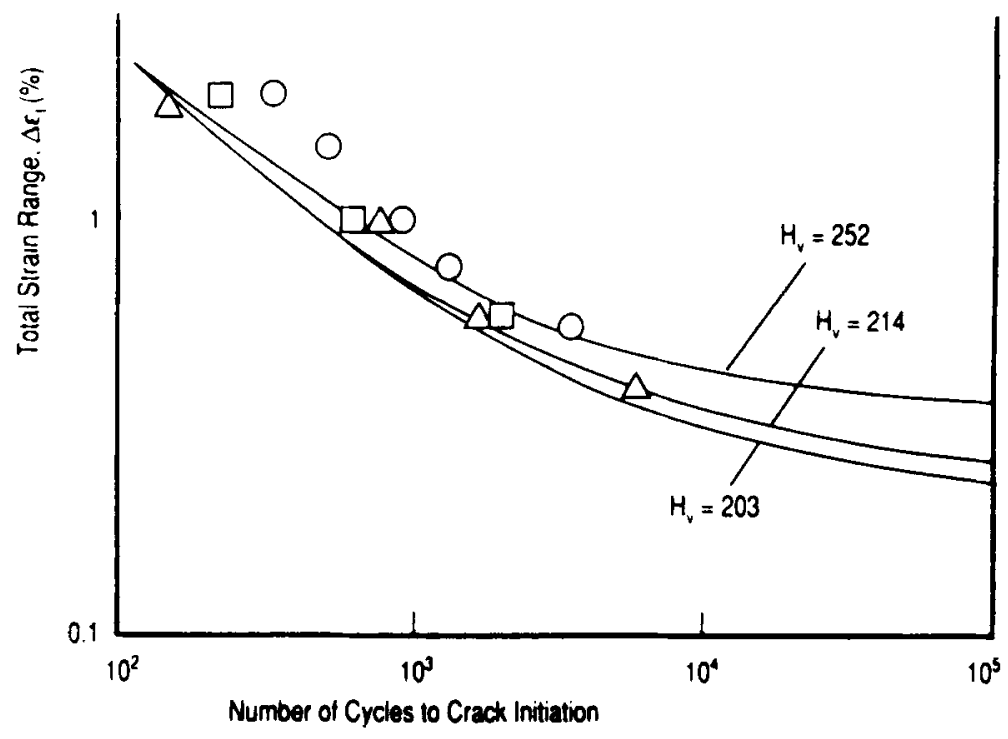

Figure 8. Estimation of low-cycle fatigue properties by hardness for a $\mathrm{Cr}-\mathrm{Mo}-\mathrm{V}$ rotor forging at $566^{\circ} \mathrm{C} . H_{v}=$ Vickers hardness number.

observed that, in boiler piping, cavitation is the principal damage mechanism at brittle zones, weld heat-affected zones, and high-stress regions in the base metal (Ellis et al 1988). In the other cases, carbide coarsening was found to be a better indicator of life consumption. A preliminary model based on carbide coarsening has also been developed (Askins 1989).

Neubauer \& Wedel (1983) characterized cavity evolution in steels at four stages isolated cavities, oriented cavities, linked cavities (microcracks), and macrocracks and formulated recommendations corresponding to the four stages of cavitation. To provide a theoretical and quantitative basis for cavity evolution, Cane \& Shammas (1984) used a constrained-cavity-growth model and proposed a relation between the number fraction of cavitated boundaries (parameter $A$ ) and the life fraction consumed using heat-specific constants. Values of these constants either had to be assumed or determined experimentally for each heat, thus restricting the usefulness of the model. Based on interrupted-creep tests on simulated heat-affected zone $1 \mathrm{Cr}-0.5 \mathrm{Mo}$ steels, Ellis and others concluded that the data had too much scatter to verify the lifeprediction model of Cane. The data could nevertheless be used empirically, by plotting all the data together in the form of a scatterband whose lower limits are defined by (Ellis et al 1989).

$$
A=0 \cdot 517\left(t / t_{r}\right)-0 \cdot 186
$$

In using the $A$ parameter method, the specific procedure used to measure $A$ is crucial. The $A$ parameter is defined as the number fraction of cavitating grain boundaries encountered in a line parallel to the direction of maximum principal stress. To measure $A$ reproducibly, the procedure needs to be standardized.

Since (12) was developed using two steels of widely different impurity concentrations, it is anticipated that the scatterband encompasses most $1 \mathrm{Cr}-0.5 \mathrm{Mo}$ steels in service. 


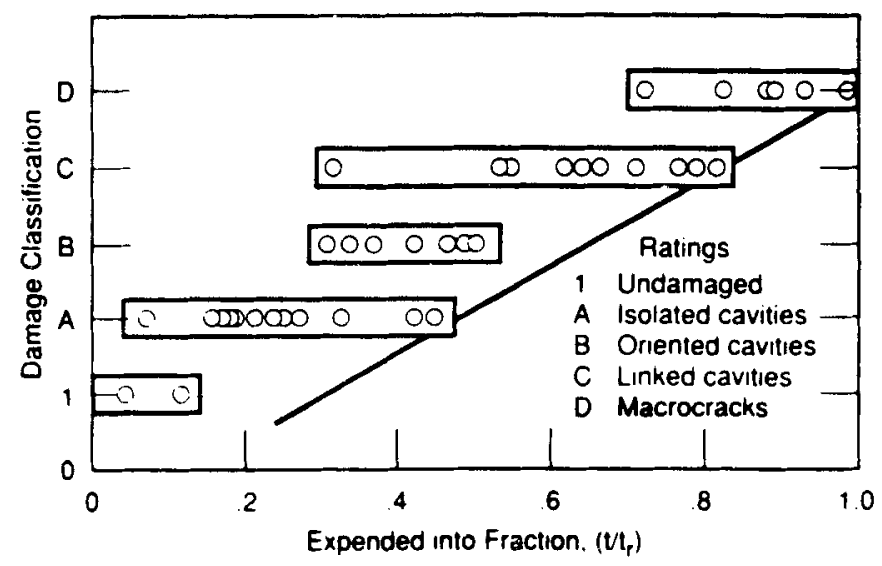

Figure 9. Correlation between damage classification and expended creep-life fraction for $1-1 / 4 \mathrm{Cr}-1 / 2$ Mo steels.

Limited data on heat-affected zone samples from $2 \cdot 25 \mathrm{Cr}-1$ Mo steels also have shown that the cavitation behaviour can be described by (12). Extension of this correlation to weld metal, to steels with fine grain size, and to other steels, however, would lead to errors.

An alternate, easier-to-use method has also been proposed by Ellis et al (1989). The damage classifications have been correlated with life fractions, and thus a life-fraction range has been established for each class (see figure 9). The Wedel-Neubauer classifications of material condition (undamaged, class A, class $B$, class $C$, and class D) correspond roughly to expended-life-fraction $\left(t / t_{r}\right)$ values of $0 \cdot 27,0 \cdot 46,0 \cdot 65,0 \cdot 84$, and 1 , respectively, using the conservative lower-bound curve shown in figure 9 . Since the expended life fraction corresponding to various damage classifications is known, the remaining life can be calculated using the relationship

$$
t_{\text {rem }}=t\left(\left(t_{r} / t\right)-1\right)
$$

where $t$ is the service life expended. The remaining life corresponding to various damage classifications can be calculated to be $2 \cdot 7 t, 1 \cdot 17 t, 0 \cdot 54 t$, and $0 \cdot 19 t$ for undamaged material, isolated cavitation, oriented cavitation, and microcracking respectively. By applying a safety factor of three to the above values, the safe reinspection intervals can be established to be $0.9 t, 0.4 t, 0.18 t$ respectively. This approach has been developed and applied by Paterson as shown in figure 10 (Paterson 1989). The figure clearly shows that the reinspection interval is not only a function of the current damage level, but also the service life elapsed, unlike in the Wedel and Neubauer approach, where the reinspection interval prescribed is independent of elapsed service life. For all combinations of damage classification and service life in regime B in the figure, the new approach results in increased inspection intervals. Several utilities that have adopted the approach have realized significant savings in inspection costs. (EPRI 1990).

The field replication data forming the basis of the Wedel-Neubauer recommendations have recently been reviewed (EPRI 1991). When these limited data were analysed, no consistent trends of cavitation evolution with operating time or with calculated creep life fraction consumed could be discerned. The laboratory data generated and analysed by Ellis and others appear to be the only available quantitative basis for setting inspection intervals. 


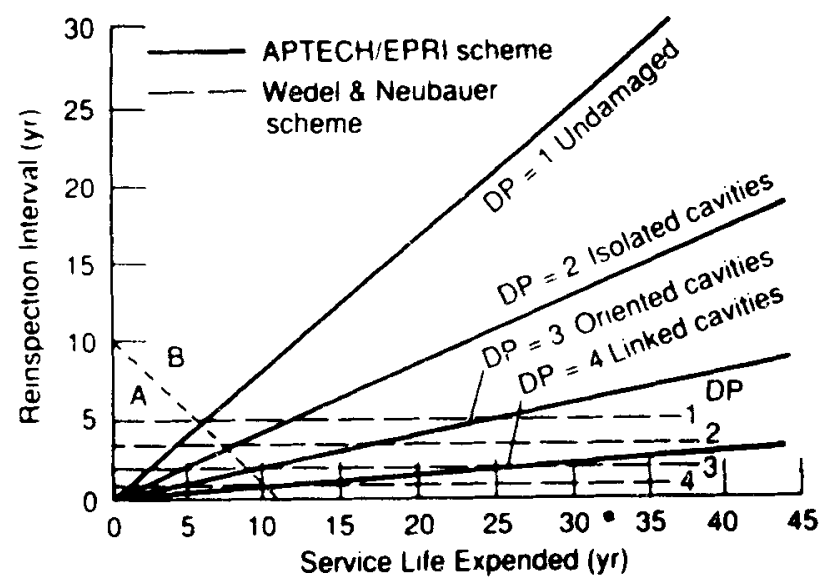

Figure 10. Service life versus reinspection interval for Aptech/EPRI remaining useful life method and the NeubauerWeidel method.

The progress of creep cavitation as a function of creep life fraction expended in $\mathrm{CrMoV}$ rotor steels has been investigated by Goto. Additional data by Carlton et al (1987) show wide variations in behaviour due to differences in grain size, ductility, and impurity contents. The results of Goto agree reasonably well with those of McGuire and Gooch for expended life fractions up to about 0.75 , but show larger values of $A$ at higher life fractions. Comparisons of the behaviour of $\mathrm{CrMoV}$ rotor steels with $\mathrm{CrMo}$ piping steels suggests that the CrMo steels cavitate more readily and reach much larger values of the $A$ parameter at failure compared to the CrMoV steels. It has also been noted that in CrMoV steels, cavitation is observed only at the end of second-stage and beginning of third-stage creep, unlike in CrMo steels where cavitation occurs during the second-stage creep (Lempp et al 1986). The relative insensitivity of the $A$ parameter to expended creep life for rotor steels makes accurate determination of the $A$ parameter crucial. For this reason, the damage classification as a function of expended life is shown in figure 11 using the lower bound curve. The life fractions consumed are estimated to be $0 \cdot 3,0 \cdot 6,0 \cdot 85$, and 1 , respectively, for undamaged and classes $A, B$, and $\mathrm{C}$ damage. These values are larger compared to CrMo steels, indicating that for a given damage classification, life consumption is higher in $\mathrm{CrMoV}$ steels, compared to CrMo steels. Blade root fixings after blade removal may be amenable to the use of replication, and cavitation has been observed in rotors at these locations. More complex equipment required for replication of rotor bores has also been developed (Goto 1985; Kadoya et al 1985). However, creep cavitation in rotor bores has not been reported to date.

\subsection{Analysis of carbides}

Askins (1989) has attempted to utilize parameters such as matrix-solute compositions, ratios of carbide phases, and matrix-lattice parameters as quantitative indices of temperature during aging of $1 \mathrm{Cr}-0.5 \mathrm{Mo}$ steels. Their data indicate a rapid initial decline in matrix-solute content and an increase in the $\mathrm{M}_{23} \mathrm{C}_{6} / \mathrm{M}_{3} \mathrm{C}$ ratio with time and temperature of aging. Changes in the matrix-solute content were also found to be reflected in changes in lattice-parameter values. Although these general trends could be 


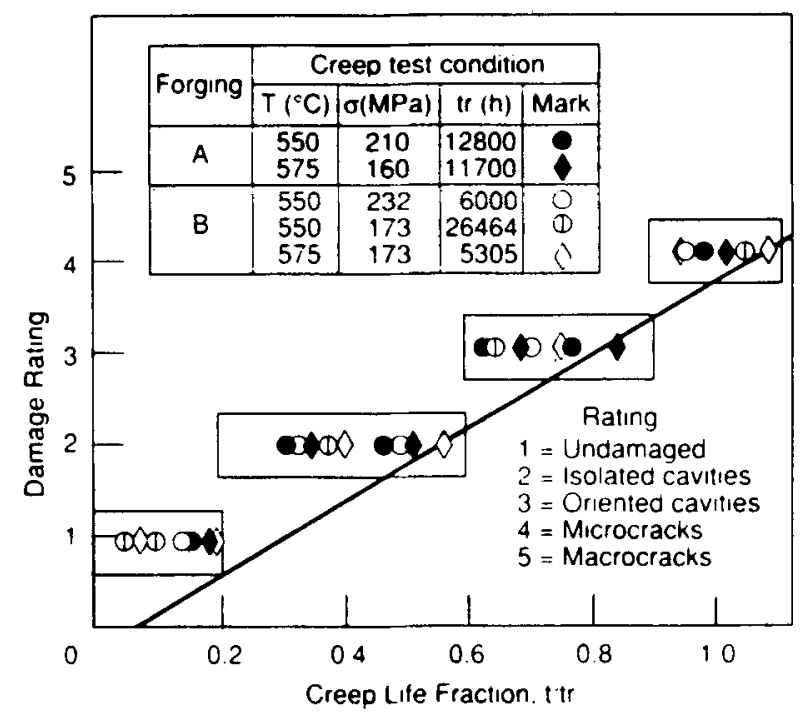

Figure 11. The correlation between damage classification and creep-life fraction for CrMoV rotor steels.

confirmed, excessive scatter in the results did not permit quantitative correlation of any of these parameters with aging history.

In $2 \cdot 25 \mathrm{Cr}-1 \mathrm{Mo}$ steels, there have been several investigations showing that prolonged exposure at about $540^{\circ} \mathrm{C}$ causes an irreversible form of embrittlement known as "carbide-induced embrittlement" (Cheruvu 1981; Qu \& Kuo 1981; Watanabe \& Shoji 1994). The embrittlement is manifested as an increase in the fracture-appearance transition temperature (FATT) and is generally associated with the formation of $\mathrm{M}_{6} \mathrm{C}$ molybdenum-rich carbides at the grain boundaries. The carbides act as sites for crack nucleation, promoting transgranular cleavage cracks at low temperatures. Carbide formation also results in softening of the steel since it depletes the matrix of the strengthening precipitate $\mathrm{Mo}_{2} \mathrm{C}$ and the molybdenum in solid solution. The softening reaction is also manifested as decreased creep strength and rupture strength.

Carbide evolution in $2 \cdot 25 \mathrm{Cr}-1 \mathrm{Mo}$ steel has been investigated by Stevens \& Lonsdale (1984), Stevens \& Flewitt (1985) and Munson (1990). In both studies, the amount of $\mathrm{M}_{6} \mathrm{C}$ carbides as a percentage of the total weight percent of carbides increased with time and temperature. Plotted in terms of a Larson-Miller timetemperature parameter, the results (figure 12) show the family of curves from the Stevens and Flewitt study to be shifted laterally by a significant amount compared to that of Munson.

These studies suggest that although the evolution of $\mathrm{M}_{6} \mathrm{C}$ may be used as a qualitative index of service temperature, wide variations may occur due to differences in initial microstructure and composition. Data in figure 12 also show that the kinetics of $\mathrm{M}_{6} \mathrm{C}$ formation are considerably accelerated by phosphorus. Improved procedures for carbide extraction as well as a larger database on samples with various initial compositions and heat treatments are needed before the microstructural techniques can be used for plant-life assessment. Stevens \& Flewitt (1985) also found that the evolution of the $M_{6} C$ phase was unaffected by stress. Nakatani et al (1990) have developed 


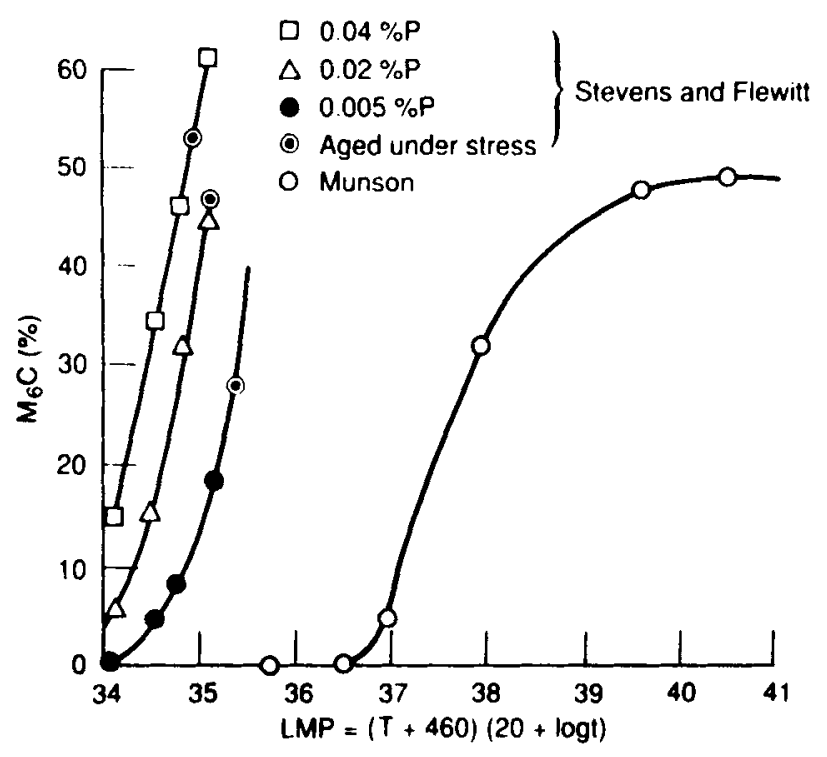

Figure 12. Evolution of $\mathrm{M}_{6} \mathrm{C}$ in $2 \cdot 25 \mathrm{Cr}-1$ Mo steel as a function of aging time and temperature. (In the equation for LMP, temperature is in degrees Fahrenheit and time is in hours.)

correlations between the percent $\mathrm{M}_{6} \mathrm{C}$ and rupture-life reduction so that the percent $\mathrm{M}_{6} \mathrm{C}$ in a service-exposed component could be used to deduce the creep-life fraction consumed.

The evolution of carbide phases in $\mathrm{CrMoV}$ rotor steels has been investigated on a single heat aged at $650^{\circ} \mathrm{C}$ by McGuire \& Gooch (1989). The percentages of $\mathrm{M}_{23} \mathrm{C}_{6}$, $M_{7} C_{3}$, and VC were found to increase appreciably with aging, with a decrease in $M_{3} C$. Most significantly, the average $\mathrm{Fe}: \mathrm{Cr}$ ratio in the carbides decreased systematically with aging. Expansion of this database to more heats and aging conditions could open the door to the widespread use of the $\mathrm{Fe}$ : $\mathrm{Cr}$ ratio in carbides as an index of degradation in these steels.

\section{Destructive tests}

Destructive tests provide a direct measure of the current damage state of the material. They are the last resort in the assessment route, since the tests require removal of samples from operating components. There are limitations on the number of available samples and locations from which they can be taken. Periodic assessment of the remaining life is not possible. The costs of cutting out material, machining samples, and conducting tests can add up to a significant expenditure. These costs are further compounded by the plant outage during the extended period of evaluation and decision making. Despite these limitations, removal of core plug samples from headers and ring samples from bore or periphery of rotors is becoming increasingly common. Destructive testing generally includes tensile, impact, and creep/stress-rupture tests. Since the purpose and limitations of the tensile and impact tests are obvious, only the creep life evaluations are described here. 


\subsection{Creep tests}

A procedure for estimating the current damage state by conducting stepped creep tests using a single specimen has been described in detail by Voorhees (1985). The procedure defines which stage of creep the material is in under service conditions but does not provide estimates of remaining life. The Monkman-Grant relationship for steels has also been in wide use and enables estimation of remaining life by determining the second-stage creep rate from creep tests. Improvements to this procedure have also been suggested by Castillo \& Khoul (1986). The most common procedure, however, continues to be the use of isostress rupture tests.

The isostress rupture test procedure consists of conducting accelerated rupture tests at a temperature above the service temperature. The stress is kept as close as possible to the service stress value. The results are plotted as $\log t_{r}$ versus $T$ and extrapolated linearly to the service temperature to estimate the remaining life. Results from recent research have identified the limitations of and possible refinements to the technique.

Results described earlier suggest that linear extrapolation of results from temperature-accelerated tests may yield optimistic predictions of remaining life under service conditions in the case of ductile materials; the reverse would be true for brittle materials. In either case, the predicted values are expected to be in agreement with the actual value within a factor of \pm 2 .

This conclusion is in agreement with that of Melton (1983). Unfortunately, it is generally difficult to define a "brittle" and "ductile" class of materials since ductility can vary from heat to heat and with the test conditions. For our purposes, we can define a "brittle" steel as one prone to creep damage by cavitation, and a ductile material as one in which creep damage occurs primarily by softening. This is consistent with the observation by the ERA researchers that the ductile case MG showed no evidence of cavitation even at a life-fraction consumption of 0.82 , while the brittle cast FW cavitated profusely. Using this definition, castings, coarse-grained heat-affected zones in welds, and fusion lines in welds may fit under the "brittle" category, while the base metal in forgings, piping, and tubes may fit in the "ductile" category. These observations are consistent with the recent results of Masuyama et al (1990) indicating differences in behaviour between ductile base metal and brittle heat- affected zones in $2.25 \mathrm{Cr}-1 \mathrm{Mo}$ steel. They further observed that in brittle heat-affected zones, both stress-accelerated and temperature-accelerated tests gave equivalent results that closely conformed to the LFR, while in the ductile base metal, only the temperatureaccelerated isostress test results were in agreement with the LFR.

Since isostress tests are normally conducted in air, oxidation correction factors are also important. The extrapolated remaining-life values obtained from the accelerated tests should be corrected for oxidation effects. If tests are conducted in inert environments, no correction factor would be needed. A further refinement to the technique consists of using miniature specimens to minimize sample requirements. It has been demonstrated that miniature specimens $(10 \mathrm{~mm}$ long, $3 \mathrm{~mm}$ diameter) tested in argon yield results representative of large specimens tested in air (Askins \& Marchant 1988; Kadoya et al 1990).

\subsection{Crack-growth studies}

All of the techniques described so far relate to life prediction from a crack-initiation 
point of view. For heavy-wall components, the initiation criteria have to be combined with crack-growth data to perform a fracture mechanics analysis of remaining life. Fatigue crack growth analysis procedures are well established. For creep-crack growth and creep-fatigue crack growth, however, methodologies and data needed for analysis have been gathered only during the last few years.

4.2a Creep crack growth: Extensive creep crack growth data pertaining to CrMo piping steels and CrMoV rotor steels have been collected, analysed, and consolidated (Saxena 1988; Saxena et al 1994). It has been observed that a crack-tip driving force parameter termed $C_{t}$, which takes time-dependent creep deformation into account, correlates much better with crack growth rates $(\mathrm{d} a / \mathrm{d} t)$ than the traditionally used elastic stress intensity factor $K$. The relation between $\mathrm{d} a / \mathrm{d} t$ and $C_{t}$ can be expressed as

$$
\mathrm{d} a / \mathrm{d} t=b C_{t}^{m} .
$$

To assess the remaining life of a component under creep-crack-growth conditions, two principal ingredients are needed: an appropriate expression for relating the driving force $C_{t}$ to the nominal stress, crack size, material constants, and geometry of the component being analysed; and a correlation between this driving force and the crack-growth rate in the material, which has been established on the basis of prior data or by laboratory testing of samples from the component. Once these two ingredients are available, they can be combined to derive the crack size as a function of time. The general methodology for doing this is illustrated below, assuming $C_{t}$ to be the driving crack-tip parameter.

The general expression for $C_{t}$ given in (14) essentially reduces to the form

$$
C_{t}=\sigma \varepsilon(A, n) a H(\text { geometry, } n),
$$

where $\sigma$ is the stress far from the crack tip, obtained by stress analysis; $\varepsilon$ is the strain rate far from the crack tip, which is a function of the constants $A$ and $n$ in the Norton relation; $a$ is the crack depth obtained from NDE measurements; and $H$ is a tabulated function of geometry and the creep exponent $n$. The values of $A$ and $n$ are either assumed from prior data or generated by creep testing of samples. By assembling all the constants needed, the value of $C_{t}$ can be calculated.

Once $C_{t}$ is known, it can be correlated to the crack-growth rate through the constants $b$ and $m$ in (14). Combining (14) and (15) provides a first-order differential equation for crack depth $(a)$ as a function of time $(t)$. Theoretically, this equation can be solved by separating variables and integrating. However, the procedure is complicated by the time-dependency of $C_{t}$ and the crack size dependence of the term $H$ in (10). To circumvent this, crack-growth calculations are performed with the current values of $\mathrm{d} a / \mathrm{d} t$ (or $a$ ), to determine the time increment required for incrementing the crack size by a small amount $\Delta a$ (i.e., $\Delta t=\Delta a / a)$. This provides new values of $a, t$, and $C_{t}$, and the process is then repeated. When the value of $a$ reaches the critical size $a_{c}$ as defined by $K_{I C}, J_{I C}$, wall thickness, remaining ligament thickness, or any other appropriate failure parameter, failure is deemed to have occurred.

Although this procedure appears complex at first sight, the calculations are relatively easy, once the principles are understood. Computer programs have been developed to perform the entire analysis on personal computers. Among these, the Steamline Inspection Code and PCPIPE are in wide use in the United States. The only judgment involved is in selecting proper values for the constants $A, n, b$, and $m$, because large 
scatter in creep and crack-growth data necessitates subjective choices. If actual creep and/or crack-growth tests could be performed, more accurate results could be obtained. Even if only the values of $A$ and $n$ in the Norton law could be pinned down by running creep tests in argon using the miniature samples described earlier, uncertainties could be reduced. A sample output may be in the form of crack depth versus time or a plot of crack size vs. remaining life, as illustrated in figure 13. This plot was generated for a thick-wall cylinder under internal pressure containing a longitudinal crack. The outside radius and wall thickness of the cylinder were assumed to be $45.7 \mathrm{~cm}$ and $7.62 \mathrm{~cm}$, respectively, and the hoop stresses were calculated for internal pressures of 8.96 and $13.79 \mathrm{MPa}$. Materials properties in the degraded condition (hot region) as well as in the undegraded condition were considered. The results show that the remaining life is a function of the stresses as well as of prior degradation. Plots of this type could be used to determine remaining life or to set inspection criteria and inspection intervals.

Ainsworth et al (1987) have recently described a unified approach for structures containing defects. This approach incorporates structural failure by rupture, incubation behaviour preceding crack growth, and creep crack growth in a single framework. Service life is governed by a combination of time to rupture, time of incubation, and time of crack growth. All of these quantities are calculated using a reference stress that is specifically applicable to the geometry of the component and is derived analytically or based on scale-model tests. If the desired service life exceeds the calculated rupture time, retirement may be necessary.

In the opposite situation, further analysis is carried out to calculate the incubation time during which no crack growth is expected to occur. If the calculation indicates that the incubation time $t_{i}$ is less than the desired service life, then a crack-growth analysis is performed to calculate the crack-growth life $t_{g}$. If the total life, $t_{i}+t_{g}$, is less than the desired service life, safe operation beyond that point would be considered undesirable. This approach seems promising and deserves further exploration.

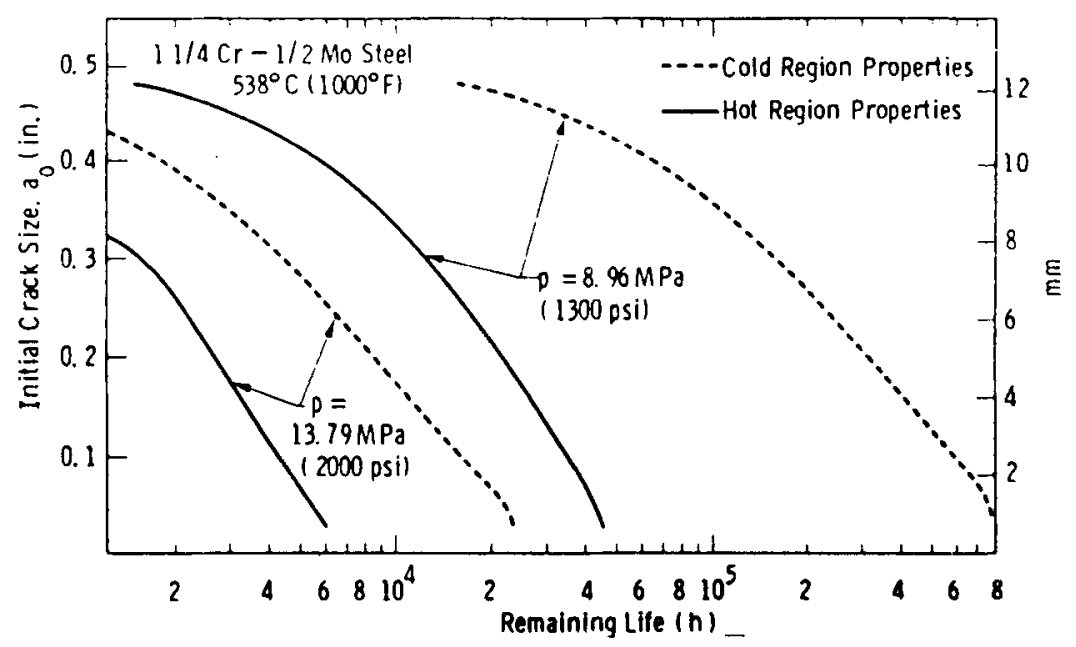

Figure 13. Remaining life as a function of initial crack size for an internally pressurized cylinder, illustrating a typical output from crack-growth analysis. 
A number of variables affect the crack growth rate by modifying $b, C_{t}$, or $m$. The effect of these variables is summarized below (Saxena 1988; Saxena et al 1994).

- In-service degradation increases crack growth rate. In ductile CrMo steel base metal, the effect was attributable to increased $C_{t}$, while in brittle CrMoV rotor steels, the effect was attributable to an increased value of $m$. Widely divergent estimates of remaining life arise due to uncertainties in the crack growth coefficients $b$ and $m$ and in the Norton law coefficients $A$ and $n$. Determination of component-specific $A$ and $n$ by miniature specimen creep tests on samples, and determination of $b$ and $m$ by creep crack growth, can greatly reduce the uncertainty in the remaining-life analysis.

- Crack growth rates at welds, fusion lines, and heat-affected zone materials are at least a factor of five higher compared to base metal.

- The presence of localized chains of inclusion, further assisted by segregation of impurities to interfaces such as grain boundaries and fusion lines, causes significant increases in creep crack growth rates.

- The presence of large amounts of impurities in the steel accelerates crack growth by increasing $m$.

- All material and experimental variables that reduce creep ductility result in higher crack growth rates.

- Temperature can have mixed effects on crack growth. In cases where the effect of temperature is merely to increase creep rate, the $\mathrm{d} a / \mathrm{d} t$ increases with increase in temperature due to increase in $C_{1}$. On the other hand, if a transition from a brittle to ductile condition is involved, increase in temperature may actually decrease the crack growth rates.

- Crack-tip constraint has a pronounced effect on crack growth. Assumptions regarding plane-stress or plane-strain conditions can have a pronounced effect on $\mathrm{d} a / \mathrm{d} t$.

- Inclusion of primary creep, in addition to the secondary creep in calculation to the secondary creep in calculating $C_{t}$, results in larger values of $\mathrm{d} a / \mathrm{d} t$ and reduced remaining life.

4.2b Creep-fatigue crack growth: Major advances have been made in developing methodologies and data needed to treat crack growth under the combined effects of creep and fatigue at elevated temperatures. The loading conditions in elevatedtemperature power generation components can often be simply represented by a trapezoidal wave shape consisting of a loading period, a hold time and an unloading period.

For these conditions, Saxena and coworkers (Saxena \& Gieseke 1987; Gieseke \& Saxena 1989; Yoon et al 1994) have suggested the following formulations for treating creep fatigue crack growth data. According to them the total crack growth rate during creep-fatigue loading can be partitioned into cycle-dependent and time-dependent components as follows:

$$
[\mathrm{d} a / \mathrm{d} n]_{\text {total }}=(\mathrm{d} a / \mathrm{d} N)_{\mathrm{fatigue}}+(\mathrm{d} a / \mathrm{d} N)_{\text {hold }},
$$

where for trapezoidal loading $(\mathrm{d} a / \mathrm{d} N)_{\text {fatigue }}$ corresponds to the crack growth rate associated with the loading/unloading portion of the cycle and $(\mathrm{d} a / \mathrm{d} N)_{\text {hold }}$ corresponds to the crack growth rate associated with the hold period. The time-dependent crack growth occurs only under constant amplitude loading during $C^{*}$ and $C_{t}$ can be used in characterizing the crack growth rate during the hold period of the cycle, $t_{h}$. Due to 
experimental limitations, it is difficult to obtain instantaneous values of $\mathrm{d} a / \mathrm{d} t$ and $C_{t}$ during the hold period. However, average values of the crack growth rate and the $C_{t}$ parameter can be accurately measured. The average $\mathrm{d} a / \mathrm{d} t$ and $C_{t}$ are obtained as follows:

and

$$
(\mathrm{d} a / \mathrm{d} t)_{\mathrm{avg}}=\left(1 / t_{\mathrm{h}}\right)(\mathrm{d} a / \mathrm{d} N)_{\text {hold }}
$$

$$
\left(C_{t}\right)_{\text {avg }}=\left(1 / t_{h}\right) \int_{0}^{t_{h}} C_{t} \mathrm{~d} t .
$$

The $(\mathrm{d} a / \mathrm{d} N)_{\text {hold }}$ is the crack growth during the hold period and is obtained by subtracting the cycle-dependent crack growth rate from the total crack growth rate.

The total crack growth rate is then given by

$$
\mathrm{d} a / \mathrm{d} N=C_{\text {fatigue }}(\Delta K)_{\text {fatigue }}^{n}+C_{1}\left[\left(C_{i}\right)_{\text {ave }}\right]^{q} t_{h}
$$

By comparing (20) with (16), it is readily seen that the first term in (19) given by the Paris Law represents the pure fatigue component and the second term represents the creep/creep fatigue component.

In test specimens, $\left(C_{t}\right)_{\text {avg }}$ can be determined from the measurements of load-line deflection as a fuction of time during the hold period. The value of $\left(C_{t}\right)_{\text {avg }}$ can be estimated by the following equation:

$$
\left(C_{t}\right)_{\text {avg }}=\left[\Delta P\left(\Delta V_{c}\right) / B W t_{h}\right] \quad\left(F^{\prime} / F\right),
$$

where $\Delta V_{c}$ is the change in load-line deflection during the hold period due to creep deformation, $\Delta P$ is the applied cyclic load, $B$ and $W$ are the thickness and width of the specimen, respectively, $F=K-$ a calibration factor $=(K / P) B W^{1 / 2}$, and $F^{\prime}=\mathrm{d} F /$ $\mathrm{d}(a / W)$. Similarly, the $(\mathrm{d} a / \mathrm{d} t)_{\text {avg }}$ can be determined by subtracting the pure fatigue crack growth component from the total $\mathrm{d} a / \mathrm{d} N$ per cycle as per (16) and dividing the resulting $(\mathrm{d} a / \mathrm{d} N)$ hold by $t_{h}$ as per (17). The $C_{t}$ average can be correlated with the $(\mathrm{d} a / \mathrm{d} t)$ average.

Figure $14 \mathrm{~b}$ shows a plot of $(\mathrm{d} a / \mathrm{d} t)_{\text {avg }}$ with $\left(C_{t}\right)_{\text {avg }}$ for $1.25 \mathrm{Cr}-0.5 \mathrm{Mosteels}$ for $538^{\circ} \mathrm{C}$. The data include test results for a 98-second hold time, ten-minute hold time, and also the creep crack growth rate data (Yoon et al 1994). When plotted as a function of $\left(C_{t}\right)_{\text {avg }}$, the time rates of crack growth for these very different conditions fall on the same trend curve, in contrast when the crack growth per cycle is plotted as a function of $\Delta K$ (see figure 14a) different curves are obtained. The significance of the above trend with regard to predicting the hold-time effect in engineering components is obvious since creep crack growth data can be used to estimate creep-fatigue crack growth data and vice versa. It must be mentioned that if $\mathrm{d} a / \mathrm{d} N$ were correlated with $\Delta K$, as has been done in the past (Saxena \& Bassani 1984), the data for each hold time will follow a different trend as shown in figure 14a. In order to use this approach for predicting crack growth during hold time it is necessary to estimate the magnitude of $\left(C_{t}\right)_{\text {avg }}$ for components. An equation has been proposed to estimate the $\left(C_{t}\right)_{\mathrm{avg}}$ for any geometry for a material deforming by elastic-cyclic plasticity and power-law creep (Yoon et al 1994). The details of this equation are given in the above reference and are outside of the scope of this overview. The applicability of this approach to steels other than $\mathrm{Cr}-\mathrm{Mo}$ steels is yet to be explored.

There are additional concerns that must be addressed in order to develop total confidence in this approach. Currently, there is no provision tc consider the interaction 

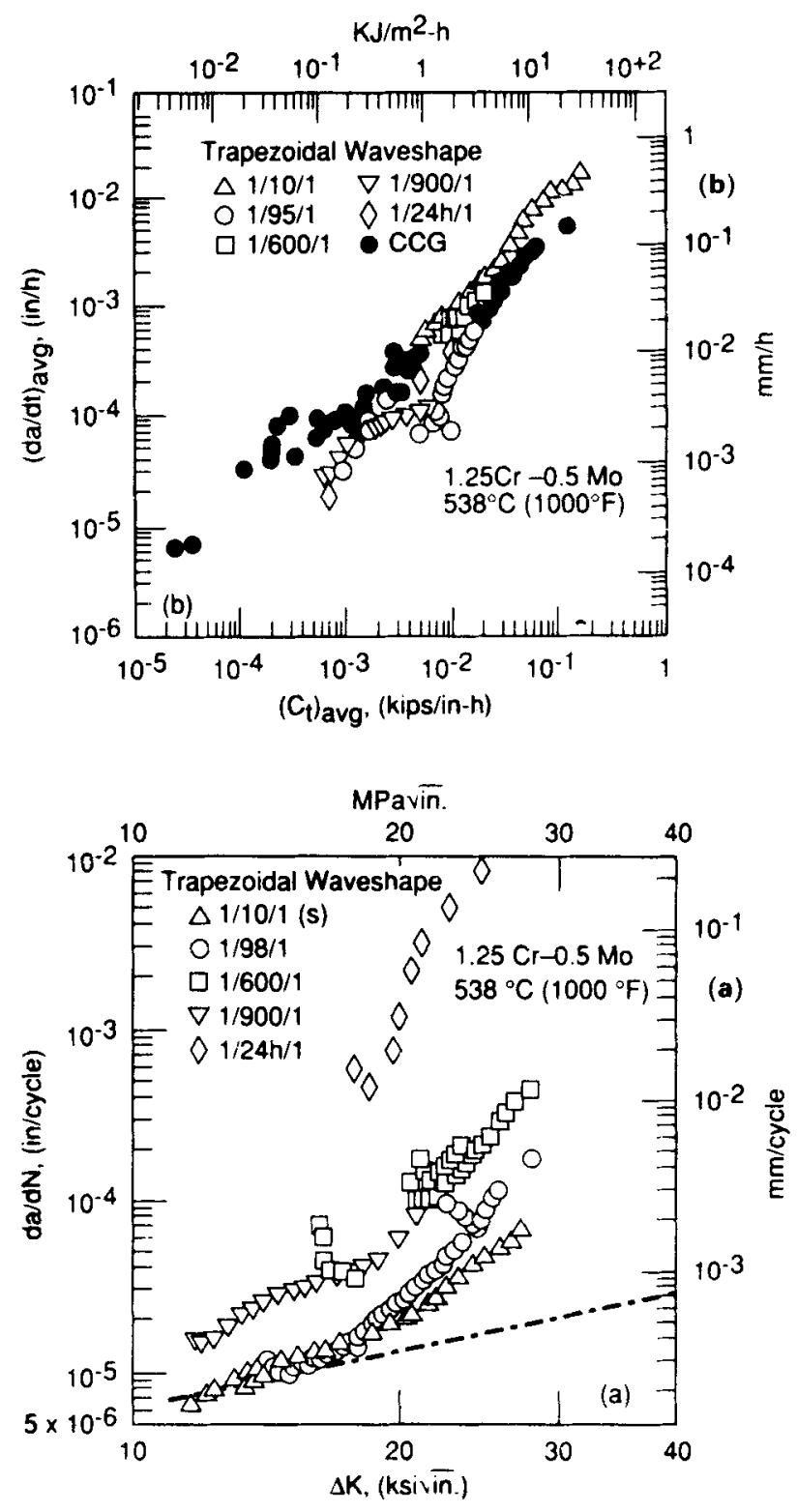

Figure 14. Comparison of creep-fatigue crack growth rates with (a) fatigue crack growth rate plotted using $\Delta K$, and (b) creep crack growth data using $\left(C_{t}\right)_{\text {avg }}$.

between loading/unloading rates and the crack growth rate during hold time. During start-up, large transient thermal stresses often develop. Therefore, the hold period may be preceded by a fatigue cycle with a maximum stress considerably higher than the stress during hold. As yet, no methods are available considering such loading. Analytical expressions for estimating $\left(C_{t}\right)_{\text {avg }}$ need further numerical verification. Also, new expressions that consider primary creep deformation are needed. The crack growth data for verification of these concepts are currently limited to a single specimen geometry. Therefore, data on a different specimen geometry must be obtained. 


\section{Nondestructive evaluation of toughness}

In heavy-section components, severe thermal stresses occurring during startup/shutdown transients can occasionally cause failures by rapid brittle fracture at relatively low temperatures. The crucial last step in remaining-life analysis of cracked components is, therefore, the determination of the critical crack size, based on a knowledge of the current toughness of the materials at the critical location. This toughness, generally expressed in terms of the plane-strain stress intensity for fracture $\left(K_{I C}\right)$ determines the critical crack size for failure. The usual procedure involves estimation of the $K_{I C}$ at low temperatures based on well-established correlations between the $50 \%$ ductile-to-brittle Fracture Appearance Transition Temperature (FATT) and $K_{I C}$. Considerable progress has been made in estimating the FATT of steels using relatively nondestructive techniques.

In $\mathrm{Cr}-\mathrm{Mo}$ steels, operating at or above $538^{\circ} \mathrm{C}$, the embrittlement mechanism of concern has been the carbide-induced embrittlement described earlier. An electrochemical polarization test has been developed by Watanabe \& Shoji (1994) for measuring the increase in FATT due to embrittlement in such cases. In CrMoV rotor steels temper embrittlement is of greater concern. The most promising techniques in this case involve the use of phosphorus versus FATT correlation, picric acid etch (PAE) tests, small punch tests, and electrochemical tests.

\subsection{Phosphorus-FATT correlations}

Viswanathan \& Gehl (1991) have performed an in-depth review of FATT data available on several $\mathrm{CrMoV}$ rotors that had been retired after 20 to 40 years of service as well as a few laboratory aged samples. The data population includes those from their work as well as additional data points from a recent paper by Seeley et al (1993). These samples were temper embrittled to varying degrees, the worst embrittlement occurring in the exposure temperature range of $370-425^{\circ} \mathrm{C}$. The FATT in the embrittled condition could be correlated with the phosphorus content of the steel, as shown in figure 15 . The D-grade rotor samples, which had been austenitized at $1,010^{\circ} \mathrm{C}$ and therefore had a coarser grain size compared to the C-grade rotor samples, exhibited slightly higher tendency to embrittle. Within limits of scatter, the post-service FATT could be estimated based on a knowledge of the phosphorus content alone.

\subsection{Small punch testing}

In the small punch test, a finished small punch (SP) specimen is placed between a $2.54 \mathrm{~mm}$ diameter hemispherical punch and a die. The punch displacement rate is controlled during the test, and a load versus deflection curve is thus developed where the area under the curve denotes the energy absorbed during the test. By conducting tests at different temperatures, a curve of absorbed energy versus temperature can be developed that is very similar in shape to that of a Charpy energy versus temperature curve, with the difference that the SP test curve is shifted laterally to lower temperatures along the temperature axis compared to the Charpy curve. The midpoint of the energy curve can be used to define a ductile-to-brittle transition temperature $\left(T_{\mathbf{s p}}\right)$. Foulds and others (Foulds et al 1991, 1993, 1994; Foulds \& Viswanathan 1994) 


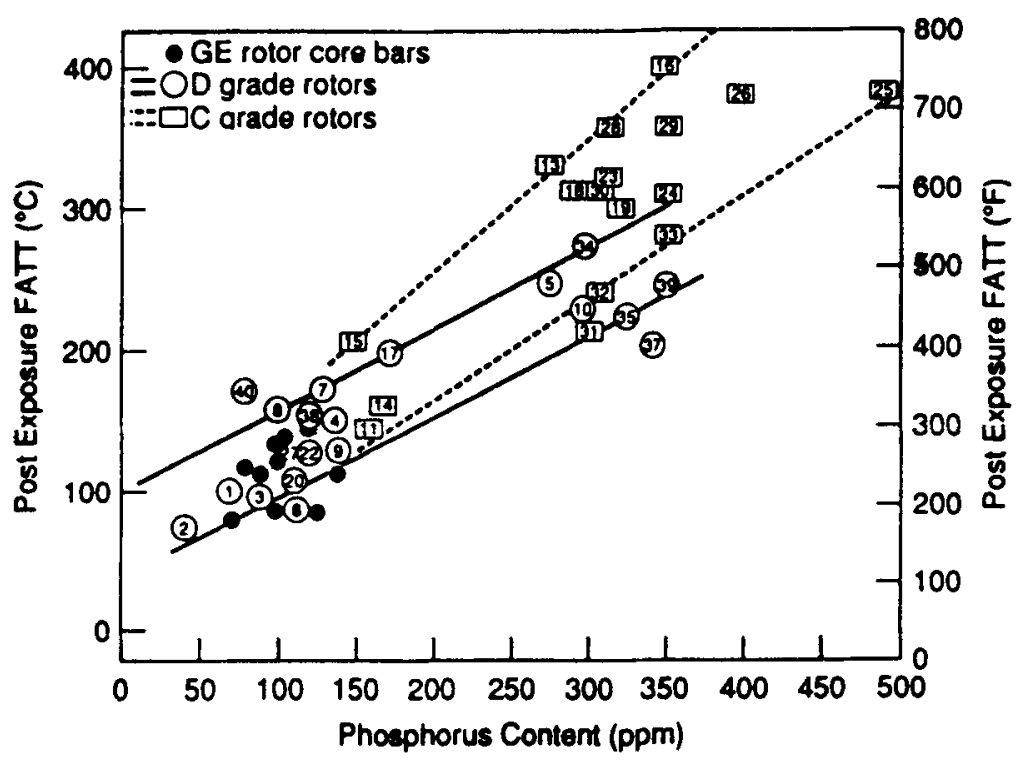

Figure 15. Variation of post exposure FATT (corrected for exposure temperature and location variations) with the phosphorus content of CrMoV rotor steel.

have successfully applied the test procedure to determine the $T_{\mathrm{sp}}$ for several retired rotor and disk samples. The $T_{\mathrm{sp}}$ values obtained correlated well with the Charpy FATT values as shown in figure 16.

The specimen needed for an SP test is only $0.508 \mathrm{~mm}$ thick with a diamter of $6.35 \mathrm{~mm}$. Specimens of this size can be easily removed from critical locations in the rotor bar without affecting the rotor integrity by using a recently developed "scoop" device. If bore samples from the critical locations were unavailable, samples from other locations could be tested and the FATT values obtained could be corrected for location dependence using the approximations described by Viswanathan \& Gehl (1991).

As stated earlier, the ultimate value of FATT in making run/repair/replace decisions is in the estimation of fracture toughness, $K_{I C}$, and the $K_{I C}$-dependent tolerable crack or defect size. A direct determination of $\mathrm{K}_{I C}$ can reduce the potential conservatism associated with the indirect FATT-to- $K_{I C}$ estimation process. Recently, the Electric Power Research Institute (EPRI) has completed preliminary development of a nonempirical, purely analytical approach to using a single small punch test to directly determine $K_{I C}$ (Foulds et al 1993, 1994). The procedure is material-independent, and requires no prior knowledge of material mechanical properties. The approach is based on the continuum material toughness concept wherein the criterion for fracture is defined and measured via the continuum stress-strain deformation properties of the material. The procedure specifically involves computing the "local" strain energy density accumulated at the location and time of crack initiation in the small punch test specimen using large-strain finite element analysis. Since the procedure also includes estimation of the material uniaxial tensile stress-strain behaviour from the small punch load-displacement curve, both the fracture toughness and the uniaxial tensile behaviour are determined from a single test. Details of the test and analysis procedures, and 


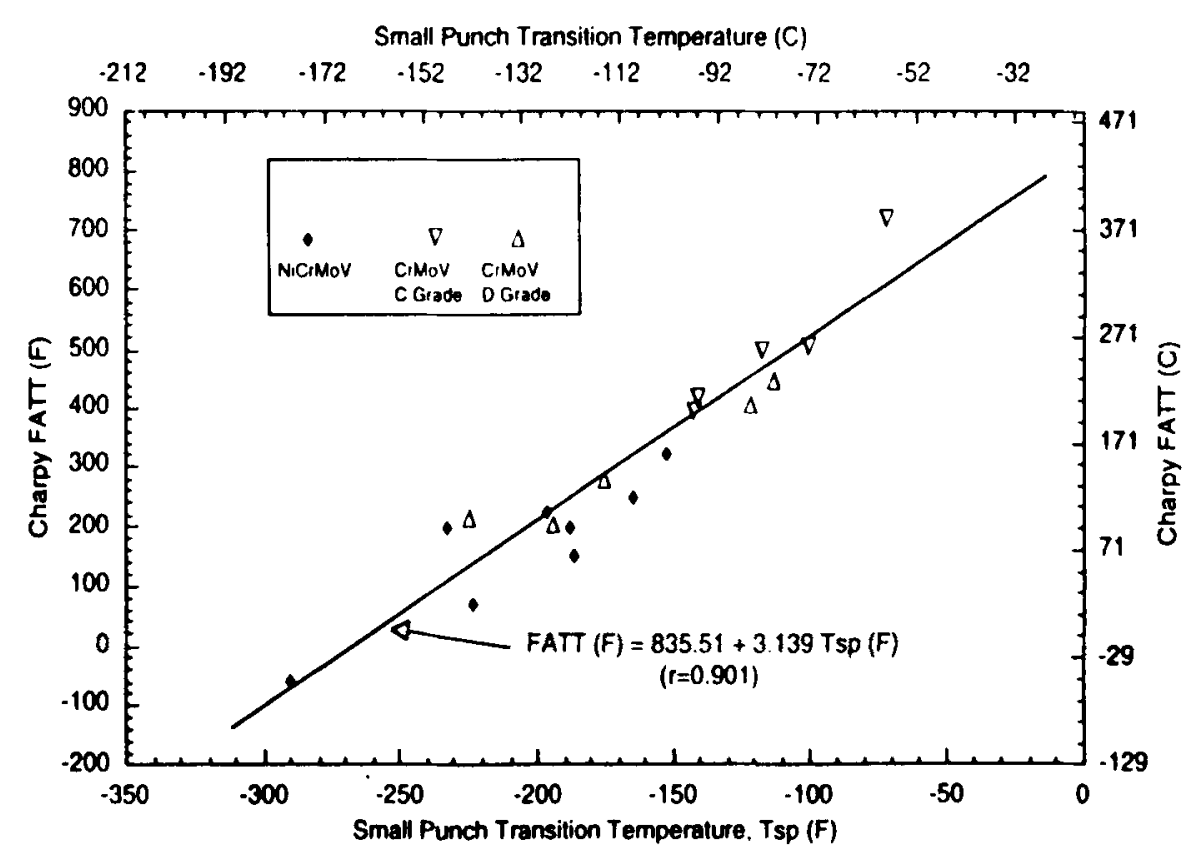

Figure 16. Correlation between Charpy transition temperature (FATT) and transition temperature measured from small punch tests $\left(T_{\mathrm{sp}}\right)$ for $1 \mathrm{Cr} 1 \mathrm{MoV}$ and 2.5 to $3 \cdot 5 \mathrm{Ni} \mathrm{CrMoV}$ rotor and disk steels.

results are contained in Foulds et al (1993). Uniaxial tensile stress-strain curves are derived from the small punch test to an accuracy of typically $<5 \%$ of the stress at any strain. With regard to fracture toughness, $K_{I c}$ prediction accuracy of the technique is about $\pm 25 \%$. This level of accuracy can result in more than a factor-of-two increase over the FATT-estimated lower bound $K_{I C}$. This translates to roughly more than a factor-of-four increase in the tolerable crack/defect size in the rotor, and a significantly increased safe-life estimate.

\section{Life-assessment for superheater tubes}

The EPRI has developed a methodology that uses measurements of steamside oxidescale thickness to predict the remaining creep life of high-temperature superheater/ reheater tubing (Paterson \& Rettig 1988; Viswanathan et al 1994). In addition, the validity of measuring the oxide-scale thickness ultrasonically has also been demonstrated by establishing a good correlation between ultrasonic measurements and direct measurements on tube samples removed from superheater assemblies from several fossil boilers. Comparison of uniaxial test results with tube burst tests results has also helped identify the correct formulas for computing the reference stress in tubing, replacing a more conservative formula used in the past. The kinetics of steam-side oxide-scale growth in heat-flux and nonheat-flux areas are also being measured in boilers. Cumulatively, these results have provided industry with the needed confidence 
in its application of a more cost-effective and nondestructive method for assessing the condition of tubing.

\section{Summary}

During the last decade major advances have been made in developing an overall strategy for assessing the remaining life of critical components operating at elevated temperatures. The strategy is based on a phased approach in which calculational, nondestructive and destructive evaluations are judiciously and sequentially linked to be most cost-effective. Research has been aimed at improving the accuracy of life prediction using all of these techniques in order to avoid undue conservatism and premature replacement of components. Key results of the research addressing both damage and crack growth phenomena under creep and creep-fatigue phenomena have been reviewed in this paper.

\section{References}

Ainsworth R A, Chell G G, Coleman M C, Goodall I W, Gooch D G, Haigh J R, Neate G J 1987 CEGB assessment procedure for defects in plant operating in the creep range. Fatigue Fracture Eng. Mater. Struct. 10: 115-127

Askins M C 1989 Remaining life estimation of boiler pressure parts. Vol. 4, Metallographic models for weld heat affected zones. EPRI Report CS-5588, EPRI, Palo Alto, CA, November

Askins M C, Marchant K D 1988 Remaining Life Estimation of Boiler Pressure Parts, Vol. 2, Miniature Specimen Testing. EPRI Report CS-5588, EPRI, Palo Alto, CA: January

Becker F L, Walker S M, Viswanathan R 1987 Guidelines for the evaluation of seam-welded steam pipes. EPRI Report CS-4774, Palo Alto

Bolton C J, Dyson B F, Williams K R 1980 Mater. Sci. Eng. 46: 231-245

Brear J M 1994 The effect of oxidation upon long-term stress rupture data of 1 CrMo and 2.25 Cr-1 Mo Steels. ERA Report 94-0504, EPRI project RP2253-4

Brear J M, McCarthy P 1989 Residual life assessment methods. ERA Report 89-0230, EPRI Project RP2253-2

Cane B J, Bissall A M 1986 Predictive assessment of damage in elevated temperature weldment. Paper presented at the EPRI Plant Maintenance Technology Conference, Houston, TX, 14-16 November

Cane B J, Shammas M 1984 A method for remanent life estimation by quantitative assessment of creep cavitation on plant. Report TPRD/L2645/N84, Central Electricity Generating Board, UK

Carlton R G, Gooch D J, Hawkes E M 1987 The central electricity generating board approach to the determination of remanent life of high temperature turbine rotors. I Mech $\mathrm{E}$ paper $\mathrm{C} 300 / 87$

Castillo R, Koul A K, Toscano E N 1986 Lifetime prediction under constant load creep condition for a cast Ni-base superalloy. (ASME paper 85, GT241 presented at the International Gas Turbine Conference, Düsseldorf, Germany, 8-12 June

Cheruvu N S 1989 Degradation of mechanical properties of steel components. Metall. Trans. A A20: 87-97

Ellis F V, Henry J F, Shammas M S 1988 Remaining life estimation of boiler pressure parts. Vol. 1, Identification of relevant damage mechanisms. EPRI Report CS-5588, EPRI, Palo Alto, CA, November

Ellis F V, Henry J F, Shammas M S 1989 Remaining life estimation of boiler pressure parts. Vol. 4, Metallographic models for weld heat affected zones. EPRI Report CS-5588, EPRI, Palo Alto, CA, November 
EPRI 1990 Field metallography research leads to improved re-examination interval for creep damaged steampipes. EPRI First Use Report B197, EPRI, Palo Alto, CA, December

EPRI 1991 Development of a replica database for life assessment of balance-of-plant components. RTUV and Failure Analysis Associates, Interim Report, EPRI Project RP2253-10, EPRI, Palo Alto, CA, January

Foulds J R, Jewett C W 1994 Miniature specimen test technique for toughness assessment. Final Report, EPRI RP1957-10, EPRI, Palo Alto, CA (in press)

Foulds J R, Viswanathan R 1994 Small punch testing for determining the material toughmess of low alloy steels. $A S M E$, J. Eng. Mater. Technol 116: 457-464

Foulds J R, Jewett C W, Viswanathan R 1991 Miniature specimen test technique for FATT. Joint Power Generation Conference (New York: ASME) 91JPGC-PWR 38

Foulds J R, Woytowitz P J, Parnell T K, Jewett C W 1993 Fracture toughness by small punch testing. In Proc. of the Third EPRI Turbo/Generator Conference (Palo Alto, CA: EPRI)

Foulds J R, Woytowitz P J, Parnell T K, Jewett C W 1994 Fracture toughness by small punch testing. Final Report on Project RP2426-38, EPRI, Palo Alto, CA

Fujiyama K, Kimura K, Muramatsu M, Yamaha M 1990 Evaluation of creep properties of degraded $\mathrm{CrMoV}$ turbine cast steels through hardness measurement and its application to life assessment. ISIJ International, 30: 869-875

Gieseke B, Saxena A 1989 Correlation of creep-fatigue crack growth rates using crack-tip parameters. Advances in fracture research (eds) K Salama et al (Elmsford, NY: Pergamon Press) pp. 189-196

Goto T 1985 Study on residual creep life estimation using nondestructive material property tests. Mitsubishi Technical Bulletin, No. 169, Mitsubishi

Grunloh H, Ryder R H 1989 General atomics, San Diego, CA, private communication of results from EPRI project RP2253-10

Harris D A, Ryder R H, Schultz C 1993 BLESS: Boiler Life Evaluation and Simulation and System - A Computer Code for Reliability. Analysis of Headers and Piping. In Reliability and risk in pressure vessels and piping (eds) J Phillips et al (New York: ASME, PVP) 251: 17-26

Hart R V 1976 Met. Technol. 3:

Xadoya Y et al 1985 Material characteristics NDE system for high temperature rotors. Presented at the ASME/IEEE Joint Power Generation Conference, Paper No. 85-JPGC, PWR-10

Kadoya Y, Goto T, Date S, Yamauchi T 1990 Assessment of remaining life of fossil power plant parts by means of miniature creep rupture test. Iron Steel Inst. Jpn. Int. 30: 853-860

Kimura K, Fujiyama K F, Muramatsu M 1988 Creep and fatigue life prediction. Hightemperature creep-fat (eds) R Ohtani M Ohnami, T Inow (Elsevier; Japan: Society of Materials Science)

Lempp W, Kasik N, Feller U 1986 Paper presented at the Second International Symposium on the Nondestructive Characterization of Materials, Montreal

Masuyama F, Nishimura N, Igari T 1990 Creep damage simulation test and creep life assessment system for elevated temperature plant components. Iron Steel Inst. Jpn. Int. 30: 885-895

McGuire J, Gooch D J 1989 Metallographic techniques for residual life assessment of $1 \mathrm{CrMoV}$ rotor forgings. International Conference on Life Assessment and Extension, Nederlands Inst. Voor Lastetechnick, The Hague, p. 116

Melton K N 1983 The isostress extrapolation of creep rupture data. Mater. Sci. Eng. 59: 143-149

Munson R 1990 Radian Corporation, Austin, TX, private communication

Nakashiro $\mathrm{M}$ et al 1991 Evaluation of long term creep strength of $2.25 \mathrm{Cr}-1 \mathrm{Mo}$ heat transfer tube in actual service stress level range. Iron Steel Inst. Jpn. Int. 30: 823-828

Nakatani H, Yokoyama T, Masuyama F, Nishimura N 1990 Metallurgical damage detection and life evaluation system for boiler pressure parts. Paper presented at the EPRI Conference on Predictive Maintenance of Fossil Plant Component, Boston, MA, October

Neubauer B, Wedel V 1983 Restlife estimation of creeping components by means of replicas. Advances in life prediction methods (eds) D A Woodford, J R Whitehead (New York: ASME) pp. 307-314

Paterson S R 1989 APTECH Engineering, Mountain View, CA, private communication

Paterson S R, Rettig T W 1988 Remaining life assessment of superheater and reheater tubes. EPRI Report CS-5564, EPRI, Palo Alto, CA 
Qu Z, Kuo K H 1981 Embrittlement of $2 \frac{1}{4} \mathrm{Cr} \mathrm{MoV}$ bolts after long exposure at $540^{\circ} \mathrm{C}$. Metall. Trans. A12: 1333-1337

Saxena A 1988 Limits of LEFM in the characterization of high-temperature fatigue crack growth. Basic questions in fatigue (eds) R P Wei. R Gangloff(Philadelphia, PA: ASTM) vol. 2, STP 924 pp. $27-40$

Saxena A 1994 Creep crack growth in CrMoV rotor steels. EPRI RP2481--5 report, EPRI, Palo Alto, $\mathrm{CA}$, in press

Saxena A, Bassani J L 1984 Time-dependent fatigue crack growth behavior at elevated temperature. Fracture interaction of microstructure. mechanisms and mechanics (Warrendale, PA: TMS) pp. 357-383

Saxena A, Gieseke B 1987 Transients in elevated temperature crack growth. Proceedings of MECAMAT - International Seminar on High Temperature Fracture Mechanism and Mechanics vol. 3, pp. 19-36

Saxena A, Han J, Banerji K 1988 Creep crack growth in boiler and steam pipe steels. EPRI Report CS-5583, EPRI, Palo Alto, CA, January

Seeley R E, Kaplan A, Bullock G S, 1993 C-Grade CrMoV steel turbine rotor life assessment. Proceedings, Third EPRI Turbine/Generator Conference (Palo Alto, CA: EPRI)

Stevens R A, Flewitt P E J 1985 The effect of phosphorus on the microstructure and creep strength of $2 \cdot 25 \mathrm{Cr}-1 \mathrm{Mo}$ steel. SER/SSD $/ 85 / 0020 / \mathrm{R}$, Central Electricity Generating Board, UK, March

Stevens R A, Lonsdale D 1984 Isolation and quantification of various carbide phases in 2.25Cr-1 Mo Steel. SER/SSD/84-0046/N, Central Electricity Gererating Board, UK, June

Viswanathan R 1989 Damage mechanisms and life assessment of high temperature components (Metals Park, Ohio: ASM)

Viswanathan $\mathrm{R} 1992$ Low cycle fatigue life prediction. In $L C F$ 3, Low cycle fatigue and elasto-plastic behavior of materials (eds) K T Rie (London: Elsevier) pp. 695-721

Viswanathan R 1993 Creep fatigue life prediction of fossil plant components. In Creep, fatigue flaw evaluation and leak before break assessment (eds) Y S Garud et al (ASME, PVP) 266: $33-51$

Viswanathan R, Gehl S 1991 A method for estimation of the fracture toughness of CrMoV rotor steels based on composition. ASME J. Eng. Mater. Technol. 113: 263-271

Viswanathan R, Gehl S M 1992 Effect of aging on the creep rupture behavior of steels. First International Conference on Microstructures and Mechanical Properties of Aging Materials (eds) P K Liaw et al (Warrendale: TMS AIME) pp. 35-41

Viswanathan R, Wells C H 1993 Life prediction of turbine generator rotors. In Technology for the $90 \mathrm{~s}-A$ decade of progress (eds) M K Au Yang et al pp. 139 179 (New York: ASME)

Viswanathan R, Patterson S R, Gounloh H 1994 Life assessment of superheater and reheater tubes in fossil boilers. J. Press. Vessel Technol. 116: 116

Voorhees H 1985 Metals handbook. 9th edn Mechanical testing (Metals Parks, Ohio: ASM) vol. 8, p. 339

Watanabe Y, Shoji T 1994 (private communication)

Wells $\mathrm{C} \mathrm{H}$, Viswanathan $\mathrm{R} 1993$ Life assessment of high energy piping. In Technology for the S0s - A decade of progress (Eds) M K Au Yang et al (New York: ASME) pp 179-217

Woodford D A 1979 J. Eng. Mater. Technol. 101:331-340

Yoon K B, Saxena A, McDowell D L 1994 Influence of crack tip cyclic plasticity on creep-fatigue crack growth. 22nd ASTM National symposium on fracture mechanics (Philadelphia, PA: ASTM) (in press) 